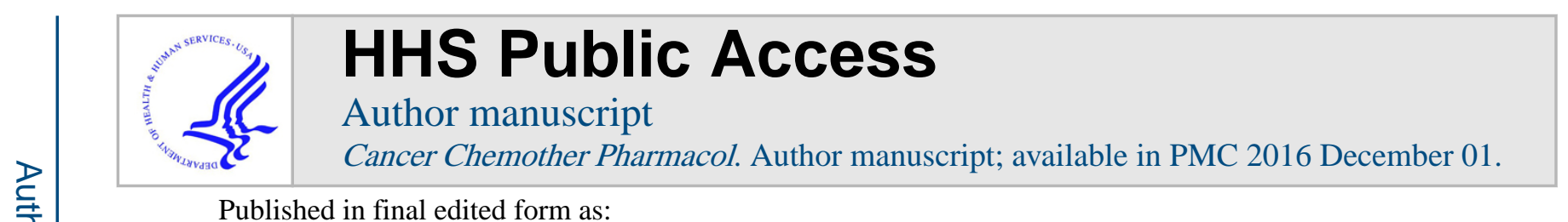

Published in final edited form as:

Cancer Chemother Pharmacol. 2015 December ; 76(6): 1113-1132. doi:10.1007/s00280-015-2861-1.

\title{
TARGETED THERAPY IN CANCER
}

\author{
Apostolia-Maria Tsimberidou, MD, PhD \\ Department of Investigational Cancer Therapeutics, The University of Texas MD Anderson \\ Cancer Center
}

\begin{abstract}
Purpose-To describe the emergence of targeted therapies that have led to significant breakthroughs in cancer therapy and completed or ongoing clinical trials of novel agents for the treatment of patients with advanced cancer.
\end{abstract}

Methods-The literature was systematically reviewed, based on clinical experience and the use of technologies that improved our understanding of carcinogenesis.

Results-Genomics and model systems have enabled the validation of novel therapeutic strategies. Tumor molecular profiling has enabled the reclassification of cancer, and elucidated some mechanisms of disease progression or resistance to treatment, the heterogeneity between primary and metastatic tumors, and the dynamic changes of tumor molecular profiling over time. Despite the notable technologic advances, there is a gap between the plethora of preclinical data and the lack of effective therapies, which is attributed to suboptimal drug development for "driver" alterations of human cancer, the high cost of clinical trials and available drugs, and limited access of patients to clinical trials. Bioinformatic analyses of complex data to characterize tumor biology, function, and the dynamic tumor changes in time and space may improve cancer diagnosis. The application of discoveries in cancer biology in clinic holds the promise to improve the clinical outcomes in a large scale of patients with cancer. Increased harmonization between discoveries, policies, and practices will expedite the development of anticancer drugs and will accelerate the implementation of precision medicine.

Conclusions-Combinations of targeted, immunomodulating, antiangiogenic, or chemotherapeutic agents are in clinical development. Innovative adaptive study design is used to expedite effective drug development.

\section{Keywords}

Targeted therapy; Molecular alterations; Bioinformatics; Precision medicine; Big data analysis

Corresponding author: Apostolia-Maria Tsimberidou, M.D., Ph.D., Department of Investigational Cancer Therapeutics, Unit 455, The University of Texas MD Anderson Cancer Center, 1515 Holcombe Boulevard, Houston, TX 77030, Phone: 713-792-4259, Fax: 713-794-3249, atsimber@mdanderson.org.

Conflict of Interest: The author declares that there is no conflict of interest. 


\section{INTRODUCTION}

The human genome project has enabled sequencing of human DNA and led to advancements in technologies that detect genomic, transcriptional, proteomic, and epigenetic changes. These technologies combined with novel drug development have accelerated the implementation of personalized medicine. Personalized medicine uses concepts of the genetic and environmental basis of disease to individualize prevention, diagnosis, and treatment.[1,2] Optimization of treatment using targeted therapy - molecules targeting specific enzymes, growth factor receptors, and signal transducers, thereby interefere with a variety of oncogenic cellular processes - and other strategies made possible by advances in translational medicine holds the promise of improving patient care.[3]

This review focuses on targeted therapy in cancer therapeutics organized according to the key drivers of carcinogenesis in humans and summarizes the current state-of-the-art applications of personalized medicine.

\section{RAS-RAF-MEK PATHWAY}

Upregulation of the mitogen-activated protein kinase (MAPK) cascades RAF (rapidly accelerated fibrosarcoma) and MEK (MAPK/ extracellular signal-regulated kinase [ERK]) contributes to carcinogenesis. Several cell-surface molecules activate RAS (KRAS, NRAS, and HRAS), a family of GTPases that activate downstream RAF protein kinases (BRAF, CRAF, and ARAF). The most important substrates of RAF kinases are MEK1 and MEK2 (MAPK/ERK kinases). MEK kinases have one main substrate, ERK.[4] Activation of ERK leads to modifications in gene expression mediated by transcription factors that control cell cycle progression, differentiation, metabolism, survival, migration, and invasion. This pathway regulates apoptosis by the post-translational phosphorylation of apoptotic regulatory molecules (Bad, Bim, Mcl-1, and caspase 9). RAS is a downstream effector of the epidermal growth factor receptor (EGFR). ERK activation promotes upregulated expression of EGFR ligands and an autocrine loop critical for tumor growth.[5] The frequency of molecular alterations in major pathway components is shown in the COSMIC database (http://www.sanger.ac.uk/genetics/CGP/cosmic/).

Melanoma-BRAF mutations are found in $62 \%$ to $72 \%$ of patients with metastatic melanoma [6] and are less frequent in radial growth phase (10\%) and in situ (5.6\%) melanomas [7]. NRAS mutations occur in 5.2\% of melanomas.[7] In conjunctival melanoma, $B R A F$ and $N R A S$ mutations were identified in $29 \%$ and $18 \%$ of patients, respectively.[8] KIT alterations were found in $36 \%$ and $39 \%$ of patients with acral and mucosal melanoma, respectively.[9] GNAQ and GNA11 alterations were found in $45 \%$ and $32 \%$ of patients with uveal melanoma, respectively.[10]

BRAF and MEK inhibitors have been approved by the U.S. Food and Drug Administration (FDA) based on their significant antitumor activity and tolerability in patients with melanoma. The FDA-approved drugs and selected investigational agents by molecular target/pathway are listed in Table 1. 
Vemurafenib and dabrafenib-Vemurafenib was the first BRAF FDA-approved inhibitor for metastatic melanoma with a $B R A F \mathrm{~V} 600 \mathrm{E}$ mutation. A phase III trial demonstrated a 3.7-month improvement in progression-free survival (PFS) in the vemurafenib arm compared to the dacarbazine arm (median PFS, 5.3 months and 1.6 months, respectively). The median overall survival (OS) was not reached in the vemurafenib arm and was 7.9 months in the control arm.[11] Dabrafenib is also FDA-approved for patients with unresectable or metastatic melanoma with a $B R A F \mathrm{~V} 600 \mathrm{E}$ mutation, based on the results of a phase III study that compared dabrafenib with dacarbazine. The median PFS was 5.1 months and 2.7 months in the dabrafenib and the dacarbazine arms, respectively.[12] Vemurafenib [13] and dabrafenib [14] have antitumor activity in patients with melanoma and brain metastases.

Trametinib-Trametinib is a MEK1/MEK2 kinase inhibitor, which was approved by the FDA as a single agent or combined with dabrafenib for unresectable or metastatic melanoma with a $B R A F \mathrm{~V} 600 \mathrm{E}$ or $\mathrm{V} 600 \mathrm{~K}$ mutation, based on the results of a randomized trial, which demonstrated longer PFS with trametinib than with chemotherapy consisting of either dacarbazine or paclitaxel in patients with stage IIIc or IV melanoma and a BRAF V600E or V600K mutation.[15] The median PFS durations were 4.8 and 1.5 months in the trametinib and chemotherapy arms, respectively (hazard ratio [HR], 0.47; P <.0001). The 6-month OS rates were $81 \%$ and $67 \%$, respectively.[15]

In a phase I-II study of dabrafenib plus trametinib or dabrafenib monotherapy in patients with melanoma and a BRAF V600E or V600K mutation, the objective response (complete response $[\mathrm{CR}]$ and partial response $[\mathrm{PR}]$ ) rates were $76 \%$ and $54 \%$, respectively $(\mathrm{p}=0.03)$. [16] Cutaneous squamous cell carcinoma (SCC), an adverse event associated with BRAF inhibitors, was less common in the dabrafenib plus trametinib group than in the dabrafenib group (7\% vs. $19 \%$, respectively).[16]

Other MEK inhibitors are in clinical trials. In a randomized phase II study in patients with BRAF-mutated advanced melanoma, selumetinib (MAP2K1/MAP2K2 inhibitor) plus dacarbazine was associated with longer PFS compared to dacarbazine (5.6 months vs. 3 months), but no improvement in OS was noted.[17]

Lung Cancer-BRAFmutations occur in 1-4\% of patients with non-small cell lung cancer (NSCLC). Molecular alterations in EGFR, ALK, ROS1, NRAS, and KRAS are also involved in the pathogenesis of lung cancer. We have noted responses in patients with NSCLC and $B R A F \mathrm{~V} 600 \mathrm{E}$ mutation treated with vemurafenib. A study of dabrafenib with or without trametinib in $B R A F \mathrm{~V} 600 \mathrm{E}-$ mutant NSCLC is ongoing.

$K R A S$ mutations are more common in smokers. In metastatic NSCLC, mutated $K R A S$ is associated with a worse prognosis than mutated EGFR. KRAS mutation was associated with shorter PFS in patients receiving maintenance erlotinib. No difference was noted in OS between mutated and wild-type KRAS.[18] In colorectal cancer (CRC), KRAS mutations are associated with resistance to cetuximab. In a phase 2 study, selumetinib combined with docetaxel was associated with a higher response rate (37\%, all PRs) in patients with KRASmutant NSCLC compared to docetaxel plus placebo (0\%).[19] Other clinical trials 
evaluating MEK inhibitors combined with chemotherapy in KRAS-mutant NSCLC have been completed (NCT01192165, NCT01362296). In a phase II randomized study of trametinib compared to docetaxel in patients with KRAS-mutant NSCLC [20], the rates of response and PFS were similar in the two arms (response, 12\% [all PR]; median PFS, trametinib: 12 weeks; docetaxel: 11 weeks). Other studies of RAS-RAF-MEK inhibitors are ongoing.

\section{PI3K-AKT-mTOR PATHWAY}

The phosphatidylinositol 3-kinase (PI3K) signaling pathway is involved in the survival, growth, metabolism, motility, and progression of cancer and is a critical pathway in cancer. [21] The PI3K family of proteins catalyzes the phosphorylation of phosphatidylinositols (PtdIns) at their 3' position; and consists of class I, II, and III. Only class IA signaling aberrations are involved in human cancers.[22] The class IA PI3Ks is composed of heterodimers of regulatory subunits (p85a, p85 $\beta, p 50 a, p 55 a$, and p55 $\gamma$ ) and catalytic subunits (p110a, p110 $\beta, \mathrm{p} 1108)$. Three genes encode the regulatory subunits: PIK3R1 encodes p85a [22] and PIK3R2 and PIK3R3 encode the p85 $\beta$ and $p 55 \gamma$ isoforms of the $p 85$ regulatory subunit, respectively. Three genes, PIK3CA, PIK3CB, and PIK3CD, encode the highly homologous $\mathrm{p} 110$ catalytic subunit isoforms $\mathrm{p} 110 \mathrm{a}, \mathrm{p} 110 \beta$, and $\mathrm{p} 110 \delta$, and share a similar five-domain structure. At the amino-terminus, there is an adaptor-binding domain that interacts with the $\mathrm{p} 85$ regulatory subunit, followed by a RAS-binding domain that mediates interaction with RAS.

The class I PI3Ks can phosphorylate the 3' position of PtdIns, PI-4-P, and PI-4,5-P 2 though PI-4,5- $\mathrm{P}_{2}$. This phosphorylation generates the second messenger phosphatidylinositol $(3,4,5)$ triphosphate $\left(\mathrm{PIP}_{3}\right)$. Cytosolic proteins, such as the AKT family of protein-serine/threonine kinases bind to $\mathrm{PIP}_{3}$ and localize to the plasma membrane in response to PI3K activation [23]. In the absence of stimulated growth conditions, baseline levels of $\mathrm{PIP}_{3}$ are undetectable in mammals. $\mathrm{PIP}_{3}$ levels at the plasma membrane are regulated by the tumor suppressor phosphatase and tensin homolog (PTEN), whose lipid phosphatase activity converts $\mathrm{PIP}_{3}$ to PI-4,5-P 2 . Loss of PTEN function through inactivating mutations, deletion, chromosomal translocation, or epigenetic silencing is the second most common initiating event in cancer, after p53 mutations.

Mutations or amplifications of the PI3K catalytic subunits $\mathrm{p} 110 \mathrm{a}(P I K 3 C A)$ and $\mathrm{p} 110 \beta$ $(P I K 3 C B)$, the PI3K regulatory subunits $\mathrm{p} 85 \mathrm{a}(P I K 3 R I)$ and $\mathrm{p} 85 \beta$ (PIK3R2), and AKT $(A K T 1)$ can activate the PI3K pathway. Mutations, deletions, or epigenetic changes in negative regulators of the PI3K axis (PTEN and inositol polyphosphate-4-phosphatase, type II) may modify tumor cell sensitivity to chemotherapy or targeted therapies.[24] AKT is the main effector of PI3K activation and has three isoforms: AKT1, AKT2, and AKT3. AKT signaling plays a significant role in cell hypertrophy, survival, hyperplasia, and metabolism. mTOR (Mammalian target of rapamycin) is the catalytic subunit of mTOR complex 1 (mTORC1) and mTOR complex 2 (mTORC2), which are distinguished by their accessory proteins, regulatory-associated protein of mTOR (RAPTOR) and rapamycin-insensitive companion of mTOR (RICTOR).[25] 
Several studies focus on targeting the PI3K-AKT-mTOR pathway. Rapamycin analogs (rapalogs) have antitumor activity in various tumors and are frequently combined with other anticancer agents.[26] Everolimus is approved for the treatment of subependymal giant cell astrocytoma; hormone receptor (HR)-positive, HER2 (Human Epidermal Growth Factor Receptor 2) -negative breast cancer (in combination with exemestane); neuroendocrine pancreatic tumors; tuberous sclerosis-associated subependymal giant cell astrocytoma; and renal cell carcinoma (sunitinib- or sorafenib-refractory). Temsirolimus, is approved for renal cell carcinoma. The efficacy of rapalogs combined with endocrine therapy for advanced breast cancer was evident in the BOLERO-2 trial, which showed a median PFS of 6.9 months for everolimus and exemestane versus 2.8 months for exemestane alone.[27]

PI3K Inhibitors-The first generation of class I pan-PI3K inhibitors targeted PI3Ka, PI3K $\beta$, PI3K $\gamma$, and PI3Kס. Wortmannin and LY294002 had limited activity. Ongoing studies are evaluating new pan-PI3K inhibitors with improved pharmacokinetic profiles and target specificity. Their antitumor activity is primarily cytostatic. Novel agents that inhibit both PI3K and mTOR may improve the antitumor activity of either agent.

GDC-0941-GDC-0941 is a selective oral class I PI3K inhibitor and at high concentrations also an mTOR inhibitor. It is being investigated in clinical trials in patients with metastatic breast cancer (NCT00960960, NCT01437566) and advanced NSCLC. Initial studies of GDC-0941 demonstrated PRs in patients with melanoma and ovarian, cervical, and estrogen receptor (ER)-positive/HER-negative breast cancer.[28-30] At the maximum tolerated dose (MTD), dose-limiting toxicities (DLTs) included grade 3 macular rash and asymptomatic Twave inversion on electrocardiograms, grade 3 thrombocytopenia, and grade 4 hyperglycemia.[29,30] Ongoing studies evaluating GDC-0941 include a phase II study in patients with untreated advanced or recurrent NSCLC treated with carboplatin/paclitaxel or carboplatin/paclitaxel/bevacizumab with or without GDC-0941 (NCT01493843). In a phase I/II study, GDC-0941 and cisplatin are being studied in patients with androgen receptornegative, triple-negative metastatic breast cancer, and in a phase II study, patients with advanced/metastatic breast cancer resistant to aromatase inhibitor therapy are being treated with GDC-0941 or GDC-0980 with fulvestrant vs. fulvestrant alone (NCT01437566). Clinical trials are also investigating combinations of PI3K inhibitors, taselisib (GDC-0032) or pictilisib (GDC-0941), with other targeted agents (e.g., palbociclib, a cyclin-dependent kinase 4 and 6 [CDK4/6] inhibitor) in advanced solid tumors or breast cancer (NCT02389842).

BKM120-BKM120 is an oral pyrimidine-derived pan-PI3K inhibitor with activity against all class I PI3K isoforms. A phase I demonstrated that BKM120 was well tolerated, with a dose-dependent safety profile.[31] Adverse events included hyperglycemia, rash, nausea, fatigue, and mood alterations. Hyperglycemia is a typical adverse event associated with the use of PI3K/AKT/mTOR pathway inhibitors. Another study demonstrated that in colorectal, breast, lung, and endometrial cancers treated with BKM120, two of 77 patients had a PR (triple-negative breast cancer with $K R A S$ and $p 53$ mutations, $\mathrm{n}=1$; and ER-positive/HERnegative metastatic breast cancer $(\mathrm{n}=1)$; both had tumor PIK3CA mutations); and $58 \%$ of patients had stable disease. 
BAY 80-6946-BAY 80-6946 is a pan-class I PI3K inhibitor with activity against PI3Ka, PI3K $\beta$, PI3K $\delta$, and PI3K $\gamma$. A phase I study demonstrated that the MTD of BAY 80-6946 was $0.8 \mathrm{mg} / \mathrm{kg}$ intravenously weekly ( 3 weeks on, 1 week off). Adverse events included hyperglycemia, fatigue, nausea, diarrhea, and mucositis. Clinical benefit was reported in patients with advanced breast, endometrial, and gastric cancers.

BEZ235-BEZ235 is an oral, reversible, and selective inhibitor of PI3K and TORC1/2. Preclinical data demonstrated antitumor activity in melanoma, breast, and colorectal cancer and sarcoma. BEZ235 suppresses cell proliferation, induces G1 cell cycle arrest, and promotes autophagy by inhibiting the activity of AKT, S6K, S6, and 4EBP1 target proteins. BEZ235 has been investigated in phase I/II clinical trials in patients with advanced cancer alone[32] or in combination with paclitaxel, trastuzumab, everolimus, or MEK162. In a phase IB study, BEZ235 combined with trastuzumab in 15 patients with HER2-positive metastatic breast cancer with altered PI3K/PTEN status was tolerable. PR and stable disease were reported in one and four patients, respectively.[33] An improved formulation of BEZ235 was used as a monotherapy or combined with trastuzumab, and stable disease was noted in $40 \%$ of patients with advanced cancer. The most common adverse events were nausea, diarrhea, elevated transaminases, and headache. The DLTs were fatigue, asthenia, grade 3 thrombocytopenia, and grade 3 mucositis.[32] A clinical trial of BEZ235 and everolimus in advanced cancer is ongoing (NCT01628913).

In prostate cancer, PTEN loss may be associated with resistance to castration.[34,35] BEZ235 causes growth arrest in PTEN-negative prostate cancers, but inhibition of the PI3K pathway leads to activation of androgen receptor (AR) signaling (inhibition of AR appears to result in promotion of PI3K activity).[35]

Other p110a isoform-specific inhibitors-Other p110a isoform-specific inhibitors, such as BYL719, GDC-0032, and INK1117 are being investigated in various solid tumors. BYL719 was associated with less hyperglycemia than the pan-PI3K inhibitor BKM120.[36] In a phase I study, BYL719 induced tumor reduction in 33\% of patients with ER-positive, metastatic breast cancer and a PIK3CA mutation.[37] Multiple studies are investigating the role of BYL719 in solid tumors as a single agent or in combination with targeted agents and cytotoxics. Although preclinical data demonstrated that PIK3CA alterations are the best biomarkers for predicting sensitivity to BYL719, p110a inhibitors are not effective in PIK3CA-mutated cells that also have a PTEN deletion. [37]

AKT Inhibitors-AKT inhibitors may induce the PI3K-stimulating receptor tyrosine kinase HER3 in breast cancer cell lines and may increase IGF-1R and the insulin receptor, thereby leading to the development of escape pathways and resistance mechanisms. Combination therapies that block the feedback response may overcome resistance to AKT inhibitors. Several studies have investigated or are investigating AKT inhibitors (such as MK2206, GSK2141795, and BAY1125976) as single agents or in combination with targeted therapies and/or chemotherapy in specific tumor types (examples: NCT01333475, NCT01902173, NCT01979523, and NCT01915576). Other drugs, such as MSC2363318A, a dual p70S6K/AKT inhibitor, are in clinical trials (NCT01971515). 
Based on the increase in tumor inhibition with combined MEK/PI3K targeting and the tolerability of drugs targeting each pathway individually, early-phase trials combining GDC-0941 (PI3K inhibitor) with GDC-0973 (MEK inhibitor), and combining BKM120 (PI3K inhibitor) with GSK1120212 (MEK inhibitor), have been completed [38,39]. The latter study demonstrated promising antitumor activity in patients with KRAS-mutant ovarian cancer.

Conclusions-In summary, molecular alterations in the PI3K/AKT/mTOR pathway have been identified in multiple tumor types, emphasizing the critical role of this pathway in tumorigenesis and disease progression. PI3K inhibitors, as single agents, have mostly cytostatic activity. Several escape mechanisms are involved in resistance to PI3K/AKT/ mTOR inhibitors. Clinical trials are exploring the role of PI3K, AKT, or mTOR inhibitors in combination with other targeted or cytotoxic agents. In our experience, patients with molecular alterations in the PI3K/AKT/mTOR pathway treated with targeted therapies have shorter survival compared to patients with alterations in the RAS/RAF/MEK or EGFR/HER/ other pathways treated with the matched targeted agents, perhaps due to less effective therapies than those for other pathways and/or intrinsic resistance (unpublished data). Carefully designed clinical trials, patient selection, and the elucidation of mechanisms of response and resistance to PI3K/AKT/mTOR pathway inhibitors, including protein, and phosphoprotein expression with signatures of sensitivity/resistance, may improve clinical outcomes.

\section{EPIDERMAL GROWTH FACTOR RECEPTOR}

EGFR (ErbB1; HER1) is a cell-surface transmembrane receptor that belongs to the EGF family of extracellular protein ligands. It is a member of the ErbB receptor family, which consists of four receptor tyrosine kinases: EGFR, HER2 (ErbB2), HER3 (ErbB3), and HER4 (ErbB4). EGF binds to EGFR, stimulating ligand-induced dimerization, receptor dimerization, and signaling through tyrosine kinase activity, leading to activation of multiple pathways involved in cell proliferation, survival, metastases, and neoangiogenesis.[40]

EGFR Targeted Therapies-EGFR targeted therapies include tyrosine kinase inhibitors (TKIs) and monoclonal antibodies. Gefitinib was the first selective EGFR inhibitor and was approved by the FDA in 2003 for NSCLC, but in 2005 the FDA withdrew this approval for use in new patients because gefitinib did not improve survival compared to placebo in previously treated patients.[41]

Erlotinib-Erlotinib targets the EGFR tyrosine kinase and is approved by the FDA for: first-line treatment of patients with metastatic NSCLC with tumor EGFR exon 19 deletions or exon 21 (L858R) substitution mutations; maintenance therapy of patients with NSCLC and no evidence of disease progression after 4 cycles of platinum-based first-line chemotherapy; and treatment of NSCLC after failure of $\geq 1$ prior chemotherapy regimen. It is approved as first-line treatment of patients with locally advanced/metastatic pancreatic cancer, in combination with gemcitabine. In NSCLC, erlotinib demonstrated a significant improvement in median PFS and OS compared to placebo.[42] EGFR kinase domain mutations predicted response to EGFR TKIs.[43,44] In patients with $E F G R$ alterations, the 
response rate to EGFR TKIs ranges from $48 \%$ to $90 \%$.[45,46] Randomized trials demonstrated that the use of gefitinib or erlotinib is associated with longer PFS compared to platinum doublets in patients with lung adenocarcinoma and activating EGFR mutations. However, no OS benefit was noted,[47-51] perhaps partially due to crossover after disease progression.

In a randomized study of erlotinib vs. placebo as maintenance therapy in patients with advanced NSCLC who had an objective response or stable disease (SD) after 4 cycles of a platinum-based doublet, erlotinib was associated with superior PFS in patients with adenocarcinoma or SCC. Survival benefit was noted only in patients with SCC.[52] The role of EGFR TKIs in patients with wild-type EGFR is unclear.[53]

The role of adjuvant erlotinib in patients with resected NSCLC and EGFR molecular alterations was investigated in a phase III trial (comparing placebo vs. erlotinib) (NCT00373425).[54] In 973 randomized patients, there was no difference in disease-free survival between the 2 arms (HR, $0.90 ; P=.32$ ). In a subset analysis of 161 patients with deletion 19 or L858R EGFR mutations, the median disease-free survival was 46.4 months in the erlotinib arm vs. 28.5 months in the placebo arm (HR, 0.61; $\mathrm{P}=.04)$. [55,56] In a phase II study (RTOG 1306, NCT01822496), patients with stage III EGFR-mutant lung cancer or ALK-positive NSCLC are randomized to erlotinib followed by concurrent chemoradiation, chemoradiation alone, crizotinib followed by concurrent chemoradiation, or chemoradiation alone.

Afatinib-Newer agents irreversibly inhibit EGFR and target additional EGFR members, such as HER2 and HER4. Afatinib is a selective, oral inhibitor of EGFR/ErbB1, HER2, and HER4. In a phase III study of afatinib or cisplatin plus pemetrexed in patients with metastatic lung adenocarcinoma with EGFR mutations, afatinib was associated with longer PFS compared to standard doublet chemotherapy (11.1 months vs. 6.9 months, respectively; $\mathrm{p}=0.001$ ).[57] In patients with exon 19 deletions or L858R mutations, the median PFS was 13.6 months. Development of resistance is attributed to additional EGFR mutations (T790M on exon 20,50\% of patients)[58] or PIK3CA mutations; MET or HER2 amplification, epithelial to mesenchymal transformation or transformation to small cell lung cancer. Novel third-generation EGFR TKIs that target T790M mutations such as CO-1686 (rociletinib) are being investigated.

Cetuximab-Cetuximab is a chimeric mouse-human immunoglobulin 1 monoclonal antibody against EGFR. It is indicated for the treatment of advanced SCC of the head and neck (combined with radiation therapy); recurrent or metastatic SCC of the head and neck (combined with platinum-based therapy with 5-fluorouracil); and recurrent or metastatic SCC of the head and neck that progresses after platinum-based therapy. Cetuximab with FOLFIRI (irinotecan, fluorouracil, and leucovorin) is indicated for the first-line treatment of K-RAS wild-type, EGFR-positive metastatic CRC; cetuximab with irinotecan for irinotecanrefractory patients; and cetuximab monotherapy is indicated for patients with oxaliplatinand irinotecan-refractory CRC or patients with irinotecan intolerance. 
The role of cetuximab in lung cancer has not been determined. In a phase III study, the addition of cetuximab to taxane/carboplatin did not significantly improve PFS or OS.[59] In another phase III study in patients with advanced EGFR-expressing NSCLC, the addition of cetuximab to cisplatin and vinorelbine was associated with improved OS compared to the cisplatin and vinorelbine arm (median OS, 11.3 months vs. 10.1 months, respectively; $\mathrm{P}=$. 04). [60] The SWOG 0819 trial comparing carboplatin/paclitaxel with and without bevacizumab (in eligible patients) and/or cetuximab in stage IV or recurrent NSCLC has been suspended (NCT00946712).

EGFR mutations and overexpression are frequent in patients with CRC [61]. In patients with irinotecan-refractory CRC, cetuximab demonstrated significant antitumor activity as monotherapy (overall response rate [ORR], 10.8\%; median time to progression, 1.5 months; median OS, 6.9 months) or combined with irinotecan (22.9\%; 4.1 months; 8.6 months, respectively).[61] In a phase III study, cetuximab was associated with improved survival compared to best supportive care in patients with refractory metastatic CRC (6.1 months vs. 4.6 months).[62] In another phase III study, first-line treatment with cetuximab plus FOLFIRI reduced the risk of progression compared to FOLFIRI alone in patients with metastatic CRC, but the benefit of cetuximab was limited to patients with KRAS wild-type tumors.[63]

In patients with previously untreated metastatic CRC, cetuximab plus FOLFOX-4 (oxaliplatin, leucovorin, and fluorouracil) was associated with a higher ORR (43\% vs. 36\%) compared to FOLFOX-4 alone.[64] In patients with KRAS wild-type CRC, cetuximab plus FOLFOX-4 compared to FOLFOX-4 alone was associated with a higher ORR (61\% vs. $37 \%, \mathrm{P}=.01)$ and a lower risk of disease progression $(\mathrm{HR}, 0.57 ; \mathrm{P}=.02)$. This study demonstrated that KRAS mutational status is a highly predictive selection criterion for the addition of cetuximab to FOLFOX-4 in this setting.[64]

Panitumumab-Panitumumab is a fully humanized IgG2 anti-hEGFR antibody, which is indicated for the treatment of patients with wild-type $K R A S$ (exon 2 in codons 12 or 13) metastatic CRC as: first-line therapy in combination with FOLFOX; and monotherapy in fluoropyrimidine-, oxaliplatin-, and irinotecan-refractory patients. In a phase III study of panitumumab with FOLFOX4 vs. FOLFOX4 alone as first-line therapy in patients with wild-type $K R A S$ metastatic CRC, the addition of panitumumab to FOLFOX4 resulted in higher rates of overall response $(57 \%$ vs. $48 \%, \mathrm{P}=.02)$, PFS (10 months vs. 8.6 months, $\mathrm{P}$ $=.01)$, and OS (HR, 0.83; $\mathrm{P}=.03)$. [65] In a randomized study of panitumumab versus cetuximab in patients with chemotherapy-refractory wild-type $K R A S$ exon 2 metastatic CRC, panitumumab was not inferior to cetuximab, and the OS benefit was similar (median OS, 10.4 months vs. 10 months, respectively; HR 0.97). [66]

KIT-The tyrosine-protein kinase KIT (c-Kit or CD117) is a receptor tyrosine kinase protein that is encoded by the KIT gene. KIT regulates cell differentiation and proliferation, resists cell apoptosis, and plays an important role in tumorigenesis and migration by activating downstream signaling molecules following interaction with stem cell factor (SCF). Complete loss of KIT activity results in in utero or perinatal death; "loss of function" leads to failure of particular stem cell populations to migrate and survive. Activating 
mutations of $K I T$ occur in almost all patients with systemic mastocytosis. In gastrointestinal stromal tumors (GIST), activating mutations of KIT occur in $>80 \%$ of patients; two-thirds of KIT mutations occur in exon 11, resulting in dysfunction of the intracellular autoinhibitory juxtamembrane domain. The majority of these mutations are indels. Deletion of exon 11 is associated with shorter PFS and OS in patients with GIST.[67] Approximately 10-15\% of KIT mutations in GIST occur in the extracellular region encoded by exon 9 (primarily in intestinal GIST). KIT mutations occur in core binding factor leukemias (17\% of AML), in up to $26 \%$ of patients with testicular seminomas and in $30 \%$ of patients with unilateral ovarian dysgerminomas. [68] Activating KIT mutations and amplifications have been reported in 5\% of patients with melanoma. In melanoma, KIT mutations occur as follows: exon 9 (5\%), exon $11(45 \%)$, exon 13 (25\%), exon 17 (10\%), and exon $18(15 \%)$; >90\% of these mutations are missense mutations. Therefore, KIT inhibition is an attractive therapeutic strategy in patients with tumor aberrations of the SCF/c-KIT signaling pathway.

Gastrointestinal Stromal Tumor-Imatinib binds directly to the ATP-binding site within KIT, competitively inhibiting ATP binding and stabilizing the kinase in the inactive conformation. In the pre-imatinib era, the median survival of patient with advanced GIST was $<1.5$ years. The use of imatinib in advanced GIST is associated with a median survival of approximately 5 years.[69] In the adjuvant setting, imatinib was associated with decreased risk of relapse after surgery with curative intent. The reintroduction of imatinib after disease relapse is associated with results inferior to those for continued imatinib therapy, suggesting that imatinib should not be interrupted.[69] Primary resistance to imatinib is noted in $10 \%$ of patients with GIST and is attributed to the type of KIT mutation (exon 9 mutations have a 3-fold higher risk of resistance than exon 11 mutations) or to suboptimal dose in patients with KIT exon 9 mutations.[70] Secondary resistance is attributed to acquired mutations in the ATP-binding site (exons 13/14) that interfere with imatinib binding or in the activation loop (exons 17/18) that stabilize the active conformation of KIT.[71] In patients with imatinib-resistant GIST tumors, sunitinib (TKI/anti-VEGF agent) demonstrated significant improvement in the median time to progression compared to placebo, leading to FDA approval for this indication.[72] The efficacy of sunitinib in imatinib-secondary resistance is attributed to structural and enzymatic characteristics of sunitinib. Other tyrosine kinases targeted by sunitinib may play a role in its efficacy.

Regorafenib is FDA-approved for TKI-resistant GIST. In a phase III study, regorafenib was associated with longer PFS than placebo (median PFS, 4.8 months vs. 0.9 months, respectively; $\mathrm{P}<.0001$ ).[73] Although antitumor activity was noted with dasatinib and sorafenib, the use of nilotinib has not shown significant antitumor activity in the third-line setting.[74]

KIT inhibitors combined with other targeted agents may improve the outcomes of patients with KIT alterations and overcome resistance. A phase I study of dasatinib and ipilimumab for unresectable or metastatic GIST or other sarcomas is ongoing (NCT01643278).

Melanoma-In patients with melanoma and a KIT alteration, the use of imatinib was associated with an ORR of 23.3\%.[75] Patients whose disease responds to imatinib typically have activating mutations in exons 11 (L576p; response, 64\%) and 13 (K462E; response, 
43\%). Other mutations in exon 11 (e.g., V559X, V560D) are also sensitive to imatinib. Wild-type KIT amplification is not sensitive to imatinib. In smaller studies, sunitinib or nilotinib also had antitumor activity [76,77].

Mastocytosis-One of the indications of imatinib is the treatment of adults with systemic mastocytosis and a non-KITD816V mutation (or unknown KIT mutation status). KIT D816V mutation, which occurs in most patients with mastocytosis, is resistant to imatinib. In a phase II clinical trial, dasatinib was associated with symptomatic benefit in patients with mastocytosis harboring a KITD816V mutation.[78] In this setting, responses have been reported with midostaurin (NCT00782067).

\section{HUMAN EPIDERMAL GROWTH FACTOR RECEPTOR 2}

As previously discussed, the HER family includes four receptors: HER1, HER2, HER3, and HER4. HER 2 is involved in the regulation of proliferation and survival of epithelial cells and is considered an orphan receptor because it has no known ligand. HER1, HER3, and HER4 receptors have ligands and form homodimers or heterodimers upon ligand binding. HER2 can heterodimerize with any of the other receptors and is the preferred dimerization partner, leading to autophosphorylation of tyrosine residues within the cytoplasmic domain of the receptors and initiating signal transduction via the PI3K/AKT and RAS/MAPK pathways.[79] In breast cancer, amplification and overexpression of the HER2 oncogene is a poor prognostic factor.[80] HER 2 overexpression occurs in approximately $15-20 \%$ of earlystage breast cancer and was historically associated with poor clinical outcomes.

Studies combining HER2-targeted therapies with other agents (PI3K, mTOR inhibitors) or immunotherapy and combinations of two or more HER2-targeted therapies (trastuzumab and TDM1; trastuzumab and pertuzumab followed by TDM1) have been completed or are ongoing (examples: NCT02073487, NCT02073916, NCT01835236 and NCT02252887).

Trastuzumab-Trastuzumab is a recombinant DNA-derived humanized monoclonal antibody that selectively binds with high affinity to the extracellular domain of HER2 protein. The antibody is an IgG1 kappa that contains human framework regions with the complementarity-determining regions of a murine antibody that binds to HER2.

Trastuzumab is indicated as monotherapy for patients with metastatic breast cancer whose tumors overexpress HER 2 protein and had $\geq 1$ chemotherapy regimen(s); and combined with paclitaxel for patients with metastatic breast cancer whose tumors overexpress HER2 protein and who have not received chemotherapy for their metastatic disease. Approximately $15 \%$ of patients develop disease recurrence after trastuzumab therapy. Resistance to trastuzumab has been attributed to altered receptor-antibody interaction, activation of the downstream pathways by increased signaling from other members of the HER family or other receptors, or constitutive activation of downstream elements. Prospective studies are assessing the role of trastuzumab in patients whose breast cancers do not overexpress HER2.

Lapatinib-Lapatinib, a dual tyrosine kinase inhibitor of EGFR and HER2, has antitumor activity in trastuzumab-refractory breast cancer. Lapitinib is FDA-approved in combination with capecitabine for patients with advanced or metastatic breast cancer whose tumors 
overexpress HER2 and who have received prior therapy, including anthracycline, taxane, and trastuzumab therapy; and letrozole for postmenopausal women with hormone receptorpositive metastatic breast cancer that overexpresses the HER2 receptor and for whom hormonal therapy is indicated.

Trastuzumab Emtansine-Trastuzumab emtansine (ado-trastuzumab emtansine, TDM1) is an antibody-drug conjugate consisting of trastuzumab linked to the cytotoxic agent mertansine (DM1). Trastuzumab inhibits the growth of cancer cells by binding to HER2, and mertansine enters and destroys cells by binding to tubulin. T-DM1 is specifically toxic to tumor cells because it targets HER2, which is overexpressed in cancer cells. In patients with HER2-positive, trastuzumab-resistant breast cancer, T-DM1 improved survival by 5.8 months compared to lapatinib and capecitabine combination therapy.[81] This study led to the FDA approval of T-DM1, which is indicated as monotherapy for patients with HER2positive, metastatic breast cancer previously treated with trastuzumab with or without a taxane. Patients receiving T-DM1 should have received prior therapy for metastatic disease, or developed disease recurrence during or within 6 months of completing adjuvant therapy.

Pertuzumab-Pertuzumab is a humanized monoclonal antibody that binds to the HER2 receptor and inhibits the interaction between HER2 and other HER family members (HER1, HER3, and HER4) on the surface of cancer cells. Pertuzumab is FDA-approved in combination with trastuzumab and docetaxel as a neoadjuvant treatment for patients with HER2-positive breast cancer and as a treatment for patients with HER2-positive metastatic breast cancer. Clinical trials are evaluating the role of pertuzumab or T-DM1, combined with standard chemotherapy and trastuzumab, for early-stage breast cancer in the adjuvant setting.

\section{CDK4/6 INHIBITORS}

In many cancer cells, CDK4 and 6 mediate cell cycle control. Randomized phase II trials in patients with ER-positive metastatic breast cancer demonstrated that CDK4/6 inhibition combined with first-line endocrine treatment can improve PFS. Clinical trials with CDK4/6 inhibitors as single agents or combined with other drugs are ongoing.

\section{ANDROGEN RECEPTOR INHIBITION}

The androgen receptor (AR) is expressed in the vast majority of ER-positive breast cancers. Interestingly, a subset of ER-negative tumors also expresses AR. Ongoing clinical trials will define the role of androgen deprivation and androgen receptor blockade in ER-positive and ER-negative tumors.

\section{BRCA1 AND BRCA2}

Hereditary BRCA1 and BRCA2 mutations are associated with an increased risk of developing breast and ovarian cancer. BRCA1/2 mutations lead to impaired double-strand DNA repair. PARP1 plays an important role in repairing single-strand breaks, and PARP1 inhibitors result in the formation of multiple double-strand breaks. Thus, the use of PARP inhibitors in tumors with BRCA1, BRCA2, or PALB2 mutations renders the cells unable to efficiently repair DNA and makes them vulnerable to apoptosis. In phase II studies in 
BRCA-associated breast cancer, the use of PARP inhibitors was associated with clinical responses.[82] Ongoing studies are comparing PARP inhibitors with standard chemotherapy in women with BRCA1/2-mutated advanced breast cancer. Clinical trials of PARP inhibitors in patients with deleterious BRCA1/2 mutations have been completed or are ongoing in breast and ovarian cancer and in other tumor types (examples: NCT01989546, NCT02326844). PARP inhibitors in clinical testing include olaparib (as a single agent or in combination with the PI3K inhibitors BKM120 or BYL713), veliparib, rucaparib, and talazoparib as single agents or in combination with cytotoxics.

C-MET

c-MET (or MET) is a receptor tyrosine kinase with specificity for a single ligand, the hepatocyte growth factor (HGF). HGF binding to MET leads to receptor dimerization and autophosphorylation of MET on its intracellular kinase domain and subsequent phosphorylation of its C-terminal docking site and juxtamembrane domain. These phosphorylation events enable activation of multiple downstream effector proteins such as the adaptor proteins Grb2 and Gab1, leading to activation of the PI3K, Ras/RAF/MEK/ERK, PLC- $\gamma$, STATs, and FAK signaling pathways. c-MET plays a role in promoting the proliferation, survival, motility, and invasion of normal and tumor cells. c-MET is thought to promote metastasis through increased production of HGF by hepatocytes, leading to enhanced paracrine signaling and clonal selection of metastatic cells with high MET expression.[83,84] c-MET promotes angiogenesis and it is involved in the development of resistance to cytotoxic chemotherapy and VEGF or EGF receptor inhibitors. c-MET and phospho-c-MET have been associated with poor clinical outcomes in patients with CRC and lung cancer and with disease progression in patients with breast cancer and melanoma. The intracellular pathways activated by c-MET interact with receptors such as EGFR, HER2, WNT, and the insulin-like growth factor receptor 1 (IGF1R). EGFR activation leads to cMET phosphorylation and activation. WNT- $\beta$-catenin pathway activation results in $M E T$ transcription.[85] c-MET activation can promote other growth receptor pathways, including the HER3-PI3K-AKT signaling pathway.[86] c-MET mutations are usually a result of sporadic somatic alterations acquired during cancer development.[86,87,84,83] Germline MET mutations are found in papillary renal cell carcinoma and familial gastric and colorectal cancer. Development of resistance to sunitinib[88], gefitinib[86], and erlotinib[87] has been in part attributed to c-MET activation. Paired analysis of tumors from patients with lung cancer whose disease stopped responding to gefitinib or erlotinib identified MET amplification as an acquired resistance mechanism in selected patients.[86]

Targeted therapy against the HGF/MET pathway includes small-molecule inhibitors and antibodies against either HGF or MET. Cabozantinib is a small-molecule inhibitor that inhibits c-Met and VEGFR2 and is FDA-approved for medullary thyroid cancer. Monoclonal antibodies include rilotumumab and ficlatuzumab. Rilotumumab was in development, but all clinical trials in advanced gastric cancer (including two phase III studies) were closed after a randomized trial demonstrated an increased death rate in the rilotumumab and chemotherapy combination arm compared to the chemotherapy arm. A phase 2 randomized, double-blind study is comparing ficlatuzumab plus erlotinib with placebo plus erlotinib in patients with previously untreated, metastatic, EGFR-mutated NSCLC and "BDX004-positive label" 
(NCT02318368). Onartuzumab is a monovalent humanized monoclonal antibody produced in E. coli, which binds to the Sema domain on the extracellular part of MET to block HGF binding. A phase III study that compared onartuzumab plus erlotinib vs. erlotinib plus placebo in patients with MET-positive advanced NSCLC was discontinued owing to the lack of clinically meaningful efficacy in an interim analysis.

Clinical trials have been completed or are in development for the monoclonal antibodies against c-MET, such as LY-2875358, h224G11A, and DN30. Synthetic small-molecule unselective (crizotinib, foretinib, cabozatinib, MGCD-265) and selective (tivantinib, JNJ-38877605, AMG337, AMG208, PF-04217903, EMD-1214063, LY-2801653, and INC-280) c-MET TKIs are being investigated. A phase III trial of tivantinib plus erlotinib for the treatment of patients with locally advanced or metastatic, non-squamous, NSCLC was discontinued because it did not meet its primary endpoint of prolonging OS.

\section{ANAPLASTIC LYMPHOMA KINASE}

ALK gene rearrangements occur in 2-7\% of patients with NSCLC. In these patients, the use of the ALK inhibitor crizotinib as first-line therapy was associated with longer PFS and less toxicity compared to chemotherapy.[89,90] Crizotinib is a small-molecule inhibitor initially developed to target c-MET (and is highly specific in this targeting) that is FDA-approved for the treatment of ALK-positive NSCLC. A phase II trial is evaluating the role of crizotinib in predefined tumor types in patients whose tumors are harboring specific alterations in ALK and/or MET (NCT01524926). The next-generation ALK inhibitors were developed to overcome resistance to crizotinib, which is attributed to secondary mutations within the ALK-TK domain, EML4-ALK amplification, bypass activation of alternative signaling pathways (EGFR, c-KIT, KRAS, IGF1 receptor), and progression/occurrence of central nervous system metastases.

Ceritinib-Ceritinib is an ATP-competitive ALK inhibitor that showed greater antitumor potency than crizotinib in preclinical studies. Ceritinib is FDA-approved (accelerated process) for patients with ALK-positive NSCLC previously treated with crizotinib. In a phase I study in patients with ALK-rearranged NSCLC $(n=114)$ who had received $\geq 400 \mathrm{mg}$ of ceritinib, the response rate was 58\%, and the median PFS was 7 months. The response rate for crizotinib-pretreated patients was 56\%. The median PFS was longer in crizotinibnaïve (10.4 months) than in crizotinib-pretreated (6.9 months) patients.[91] In an expansion cohort of 246 patients with ALK-rearranged metastatic NSCLC treated with the MTD of $750 \mathrm{mg}$ orally daily, the response rate was $58.5 \%$ (ALK-inhibitor pretreated, 54.6\%; ALK inhibitor-naïve, 66.3\%), and the median PFS was 8.2 months (6.9 months and not reached, respectively). CNS responses were noted in some patients with untreated lesions.

A randomized trial for patients with ALK-rearranged metastatic NSCLC previously untreated or treated with chemotherapy and crizotinib is comparing ceritinib with pemetrexed/cisplatin or pemetrexed/carboplatin (NCT01828099). A phase III trial is comparing ceritinib with standard chemotherapy in patients with ALK-rearranged NSCLC. Other studies are investigating ceritinib as monotherapy in cholangiocarcinoma with ROS1 or ALK overexpression or in anaplastic/undifferentiated thyroid cancer with ALK alterations 
or in combination with targeted therapies or chemotherapy, such as with everolimus, in solid tumors and ALK-rearranged NSCLC, with chemotherapy in pancreatic cancer, with LEE011 in ALK-positive NSCLC, and with nivolumab in NSCLC.

Alectinib-Alectinib is another second-generation ALK inhibitor. In a phase I/II study of alectinib in ALK inhibitor-naïve patients with metastatic ALK-rearranged NSCLC, no DLTs were noted up to doses of $300 \mathrm{mg}$ twice daily, and the response rate was $93.5 \%$. In another phase I/II study in patients with ALK-rearranged tumors who had progressed on crizotinib treatment, the MTD of alectinib was $600 \mathrm{mg}$ twice daily. The response rate during the dose escalation part of the study was 55\%. In patients with known CNS metastases treated with alectinib, the response rate was $52 \%$ within the CNS. No patient initially free of CNS metastases developed new CNS lesions during treatment. A phase III trial is comparing alectinib to crizotinib in treatment-naïve patients with advanced ALK-rearranged NSCLC.

Other ALK Inhibitors-Another ALK inhibitor with antitumor activity in NSCLC is AP26113, which has activity against ALK and mutant isoforms of EGFR without activity against EGFR wild-type. Preliminary data from a phase I/II trial in crizotinib-pretreated patients demonstrated a response rate of 63\%. ASP3026 is a selective, ATP-competitive ALK inhibitor with activity against wild-type ALK and against the most frequent crizotinib resistance-mediating gatekeeper mutation, L1196 M. In a phase I trial, the MTD was $125 \mathrm{mg}$ and $44 \%$ of patients with crizotinib-resistant ALK-rearranged NSCLC had a PR. TSR-011 is an inhibitor with antitumor activity against ALK and tropomyosin-related kinase. PD-06463922 is a TKI with activity against ALK and ROS1, which appears to retain its signal-blocking effects even when several ALK mutations, leading to crizotinib resistance, are present. X-396 is a small-molecule TKI blocking ALK signaling in the wild-type conformation and with considerable activity against at least two of the crizotinib resistancemediating ALK point mutations (L1196 M and C1156Y). An ongoing phase I study demonstrated promising activity (NCT01625234). The heat shock protein 90 (HSP90) inhibitors have also demonstrated activity against ALK-rearranged NSCLC in early clinical trials. In a phase II trial of the HSP90 inhibitor ganetespib, PRs were noted in 4 of 98 patients.[92] The HSP90-inhibiting compound AUY922 has shown promising activity.

\section{NOTCH}

Notch was identified as an oncogene in T-cell acute lymphoblastic leukemia (T-ALL) in which the $(7 ; 9)$ chromosomal translocation fuses the $\mathrm{N}$-terminal region of the T-cell receptor beta (TCR $\beta$ ) to the C-terminus of Notch1. This leads to expression of a truncated Notch1 protein that lacks the extracellular subunit and is thus constitutively active.[93] The intracellular forms of all four Notch proteins are potentially oncogenic and capable of transforming normal cells. Deregulated expression of Notch proteins, ligands, and targets has been described in various solid tumors, including cervical, head and neck, endometrial, renal, lung, pancreatic, breast, ovarian, prostate, esophageal, hepatocellular, and gastric carcinomas, osteosarcoma, mesothelioma, melanoma, glioma, medulloblastoma, and rhabdomyosarcoma. They have also been found in T-ALL, Hodgkin lymphoma, anaplastic large-cell NHL, AML, B-cell CLL, and multiple myeloma. Notch may contribute to carcinogenesis by inhibiting differentiation, inhibiting apoptosis, or promoting proliferation. 
The intracellular forms of Notch induce transformation when it is expressed with oncoproteins that disable the G1-S checkpoint, such as adenovirus E1A, human papillomavirus E6 and E7, Ras, Myc, or SV40 large T-antigen. Notch can activate the expression of several oncogenic pathways via direct or indirect induction of cyclins D1, D3, and A, SKP2, and c-Myc or via activation of PI3K-AKT-mTOR, NF- $\kappa$ B and NF- $\kappa$ B2, $\beta$ catenin, or signal transducer and activator of transcription-3. Notch can also co-operate with oncogenic pathways such as WNT or HER2/Neu.

In addition to its cell-autonomous effects on oncogenic pathways, Notch is involved in tumor-stroma interactions and has a tumor suppressor effect in the epidermis. Notch activity has been reported in cancer stem-like cells (CSCs), which constitute a small subset of cancer cells with a stem-like phenotype that are a reservoir of self-sustaining cells with the ability to self-renew, presumably leading to recurrence. The stem-like phenotype is characterized by enhanced resistance to chemotherapy and radiotherapy, supporting the role of Notch signaling in the maintenance of breast CSCs. Neutralizing monoclonal antibodies directed against Notch 1, 2, and 3 have been used in the clinic. A phase I study of OMP-59R5, a humanized mAb that blocks Notch 2 and Notch 3 signaling, was followed by two phase $1 \mathrm{~b} / 2$ trials: the "ALPINE" trial (Antibody therapy in first-Line Pancreatic cancer Investigating anti-Notch Efficacy and safety), which is testing OMP-59R5 with gemcitabine and abraxane as first-line therapy in patients with advanced pancreatic cancer and the "PINNACLE" trial (Phase 1b/2 Investigation of anti-Notch Antibody therapy with Cisplatin and etoposide in small cell Lung carcinoma Efficacy and safety), which is testing OMP-59R5 combined with cisplatin and etoposide as first-line therapy in patients with extensive-stage small cell lung cancer.

Soluble Dll4-Fc fusion proteins, that bind Notch receptors and prevent their activation by endogenous Dll4, inhibit Notch signaling in endothelial cells, causing disorganized angiogenesis, and inhibiting tumor growth. Clinical trials using the OMP-21M18 antibody are ongoing for patients with pancreatic cancer (as first-line therapy with or without abraxane), small cell lung cancer (with carboplatin and pemetrexed), and platinum-resistant ovarian cancer (with paclitaxel).

Non-selective $\boldsymbol{\gamma}$-secretase inhibitors (GSIs) are also known as "Notch inhibitors". The GSI MK-0752 is being investigated in clinical trials in solid tumors and T-ALL. In a phase I trial, MK-0752 was combined with gemcitabine in patients with pancreatic ductal adenocarcinoma.

In a phase $1 \mathrm{~b}$ trial of the GSI RO4929097 combined with exemestane in metastatic, ERpositive breast cancer, treatment was tolerable and responses were noted (NCT01149356). The development of RO4929097 has been hampered by its pharmacokinetic liability due to the auto-induction of hepatic metabolism. GSI PF-03084014 is currently in phase 1 clinical trials for TALL and various solid tumors (NCT01981551).

In summary, deregulation of Notch proteins has been associated with cancer development and progression and with the self-propagation of CSCs. Notch-targeted therapies include non-selective GSIs, but various other agents are in development. In HER2-positive breast 
cancer the effect of Notch inhibition was recurrence prevention rather than tumor volume decrease.

\section{FIBROBLAST GROWTH FACTOR RECEPTOR}

The fibroblast growth factor receptor (FGFR) family comprises four main members (FGFR1-FGFR4) and encodes membrane tyrosine kinase receptors involved in signaling by interacting with fibroblast growth factors. FGFR 3 and $F G F R 4$ activating mutations exist [94,95], but amplification of $F G F R 3$ and $F G F R 4$ has been described very rarely in cancer. According to the public Cancer Genome Atlas (http://cancergenome.nih.gov), FGFR1 amplification occurred in $3.4 \%$ of 10,648 patients and $F G F R 2$ amplification occurred in $0.9 \%$ of 8,352 patients. The amplifications were found in lung (16.9\%), breast (13.4\%), and gastric cancer (5.1\%). FGFR1 amplification has been found in lung cancer, SCC of the head and neck, esophageal SCC, breast, and pancreatic cancer. FGFR2 amplification has been found in gastric and breast cancer and NSCLC. In a meta-analysis, it was shown that amplification of FGFR1 or FGFR2 may be associated with poor OS in various cancers.[95] $F G F R 1$ amplification was also associated with shorter disease-free survival.

In a phase II study of brivanib (an oral, multi-targeted TKI with activity against VEGF and FGFR) in recurrent or persistent endometrial cancer, the ORR was 18.6\% (8 of 43 patients; $\mathrm{CR}, \mathrm{n}=1 ; \mathrm{PR}, \mathrm{n}=7$ ), and 13 patients were progression-free at 6 months.[96] Dovitinib (TKI258) is a TKI that inhibits FGFR, VEGFR, and platelet-derived growth factor receptor. [97] In a phase II study of dovitinib in metastatic renal cell carcinoma, of 67 patients enrolled, $82.1 \%$ were previously treated with $\geq 1$ VEGFR TKI and $\geq 1$ mTOR inhibitor. The rates of 8 -week overall response and disease control were $1.8 \%$ and $52.7 \%$, respectively. The median PFS and the median OS were 3.7 and 11.8 months, respectively.[97] In a phase II trial of dovitinib in 81 patients with metastatic breast cancer, unconfirmed response or stable disease for $>6$ months was observed in five (25\%) and one (3\%) patient(s), respectively, with FGFR1-amplified/HR-positive or FGFR1-nonamplified/HR-positive breast cancer. Other FGFR inhibitors that are being investigated in clinical trials include AZD4547, BAY1187982, BIBF1120, lucitanib (VEGFRFGFR inhibitor), ponatinib, TAS-120, Debio 1347 (CH5183284), BAY1163877 (pan-FGFR inhibitor), FGF401, BGJ398 (as monotherapy or combined with BYL719), nintedanib, JNJ-42756493, GSK3052230 (combined with paclitaxel and carboplatin or docetaxel or as monotherapy), ARQ 087, BAY1179470, and FPA144. Clinical trials that set FGFR copy number as an inclusion criterion and standardization of FGFR amplification testing may improve these trials.[95]

\section{INSULIN-LIKE GROWTH FACTOR RECEPTOR}

Insulin-like growth factor (IGF) signaling plays a critical role in the growth and survival of many types of human cancer cells. Although preclinical data of several inhibitors of GF1R were promising in early-phase clinical trials, serious toxicities were observed. Larger randomized phase III trials of targeting this pathway failed and led to termination of the antiIGF1R programs.[98] 


\section{P53 MDM2 INHIBITORS}

Clinical trials with other inhibitors, such as the murine double minute 2 (MDM2) inhibitor DS-3032b; RO6839921; RO5045337 in combination with doxorubicin in soft tissue sarcoma; RO5503781; HDM201 in combination with LEE011 in liposarcoma; and HDM201 in TP53 wild-type advanced tumors, are ongoing or have been completed, and to date they have demonstrated limited, if any, antitumor activity.

\section{FUTURE PERSPECTIVES}

Breakthroughs in technology and the discovery of effective drugs have led to epic advances in the war against cancer. We first demonstrated that in early-phase clinical trials across tumor types, targeted therapy is associated with high rates of response, PFS, and survival in patients with one targetable molecular alteration. $[1,99,100]$ Next-generation sequencing, circulating DNA and tumor cells, and other profiling will improve our understanding of tumor biology in individual patients. Currently, there is a gap between the plethora of preclinical data and the lack of effective therapies, which is at least partially due to suboptimal drug development for "driver" alterations of human cancer, the high cost of clinical trials and available drugs, and limited access of patients to clinical trials. The complexity of the development of anticancer drugs is evidenced by the high rate of failure of phase III clinical trials of various agents that showed promising results in early-phase studies. Ongoing clinical trials with innovative adaptive study design hold the promise of expediting effective drug development (NCT02152254, NCT01827384, NCT01771458, NCT01248247, NCT01042379, NCT02117167).

Further advances in cancer therapy will be associated with the improved technology and bioinformatic analyses to understand dynamic changes in biology and tumor plasticity. Vertical access (changes in time) of cancer biological components to address molecular evolution and horizontal access (changes by site of disease involvement) to address tumor heterogeneity, the interaction between the cancer genome and the epigenome, and the surrounding microenvironment, need to be considered. The computational sciences are expected to accelerate drug development by establishing methods to charactarize the molecular interactions and analyze a large amount of data about activated pathways, crosstalk and interactions between various components of the cancer intra-cellular machinery. The power of computational medicine and data sharing is stimulating investigators to develop promising projects that involve the implementation of both bioinformatics and big data analyses. Finally, the development of effective therapeutic strategies, carefully designed clinical trials, and collaborative efforts among key stakeholders in cancer therapy ultimately hold the promise of curing cancer.

\section{Acknowledgments}

Funding: This work was supported by the National Cancer Institute at the National Institutes of Health under grant P30CA016672.

\section{ABBREVIATIONS}
AR
androgen receptor 


\begin{tabular}{|c|c|}
\hline CSCs & cancer stem-like cells \\
\hline CRC & colorectal cancer \\
\hline $\mathbf{C R}$ & complete response \\
\hline DFS & disease-free survival \\
\hline DLTs & dose-limiting toxicities \\
\hline EGFR & Epidermal Growth Factor Receptor \\
\hline ERK & extracellular signal-regulated kinase \\
\hline FGFR & fibroblast growth factor receptor \\
\hline FDA & Food and Drug Administration \\
\hline GIST & gastrointestinal stromal tumors \\
\hline GSIs & non-selective $\gamma$-secretase inhibitors \\
\hline HR & hazard ratio \\
\hline HGF & hepatocyte growth factor \\
\hline HER2 & human epidermal growth factor receptor 2 \\
\hline IGF & Insulin-like growth factor \\
\hline KIT & tyrosine-protein kinase \\
\hline mTOR & Mammalian target of rapamycin \\
\hline mTORC1 & mTOR complex 1 \\
\hline mTORC2 & mTOR complex 2 \\
\hline MTD & maximum tolerated dose \\
\hline MAPK & mitogen-activated protein kinase \\
\hline MDM2 & murine double minute 2 \\
\hline NSCLC & non-small cell lung cancer \\
\hline OS & overall survival \\
\hline PTEN & phosphatase and tensin homolog \\
\hline PtdIns & phosphatidylinositols \\
\hline PI3K & phosphatidylinositol 3-kinase \\
\hline PR & partial response \\
\hline PFS & progression-free survival \\
\hline
\end{tabular}




$\begin{array}{ll}\text { RAF } & \text { rapidly accelerated fibrosarcoma } \\ \text { RAPTOR } & \text { regulatory-associated protein of mTOR } \\ \text { RICTOR } & \text { rapamycin-insensitive companion of mTOR } \\ \text { SCF } & \text { stem cell factor } \\ \text { SCC } & \text { squamous cell carcinoma } \\ \text { T-ALL } & \text { T-cell acute lymphoblastic leukemia } \\ \text { TCR } \beta & \text { T-cell receptor beta } \\ \text { T-DM1 } & \text { trastuzumab emtansine (ado-trastuzumab emtansine) } \\ \text { PIP } & \text { triphosphate } \\ \text { TKIs } & \text { tyrosine kinase inhibitors }\end{array}$

\section{REFERENCES}

1. Tsimberidou AM, Iskander NG, Hong DS, Wheler JJ, Falchook GS, Fu S, Piha-Paul S, Naing A, Janku F, Luthra R, Ye Y, Wen S, Berry D, Kurzrock R. Personalized medicine in a phase I clinical trials program: the MD Anderson Cancer Center initiative. Clinical cancer research : an official journal of the American Association for Cancer Research. 2012; 18(22):6373-6383. doi: 10.1158/1078-0432.CCR-12-1627. [PubMed: 22966018]

2. Von Hoff DD, Stephenson JJ Jr. Rosen P, Loesch DM, Borad MJ, Anthony S, Jameson G, Brown S, Cantafio N, Richards DA, Fitch TR, Wasserman E, Fernandez C, Green S, Sutherland W, Bittner M, Alarcon A, Mallery D, Penny R. Pilot study using molecular profiling of patients' tumors to find potential targets and select treatments for their refractory cancers. Journal of clinical oncology : official journal of the American Society of Clinical Oncology. 2010; 28(33):4877-4883. doi:JCO. 2009.26.5983 [pii] 10.1200/JCO.2009.26.5983. [PubMed: 20921468]

3. Tsimberidou AM, Eggermont AM, Schilsky RL. Precision cancer medicine: the future is now, only better. Am Soc Clin Oncol Educ Book. 2014; 34:61-69. doi:10.14694/EdBook_AM.2014.34.61 00114000061 [pii]. [PubMed: 24857061]

4. Tidyman WE, Rauen KA. The RASopathies: developmental syndromes of Ras/MAPK pathway dysregulation. Current opinion in genetics \& development. 2009; 19(3):230-236. doi:10.1016/j.gde. 2009.04.001. [PubMed: 19467855]

5. Roberts PJ, Der CJ. Targeting the Raf-MEK-ERK mitogen-activated protein kinase cascade for the treatment of cancer. Oncogene. 2007; 26(22):3291-3310. doi:10.1038/sj.onc.1210422. [PubMed: 17496923]

6. Dong J, Phelps RG, Qiao R, Yao S, Benard O, Ronai Z, Aaronson SA. BRAF oncogenic mutations correlate with progression rather than initiation of human melanoma. Cancer research. 2003; 63(14): 3883-3885. [PubMed: 12873977]

7. Poynter JN, Elder JT, Fullen DR, Nair RP, Soengas MS, Johnson TM, Redman B, Thomas NE, Gruber SB. BRAF and NRAS mutations in melanoma and melanocytic nevi. Melanoma research. 2006; 16(4):267-273. doi:10.1097/01.cmr.0000222600.73179.f3. [PubMed: 16845322]

8. Griewank KG, Westekemper H, Murali R, Mach M, Schilling B, Wiesner T, Schimming T, Livingstone E, Sucker A, Grabellus F, Metz C, Susskind D, Hillen U, Speicher MR, Woodman SE, Steuhl KP, Schadendorf D. Conjunctival melanomas harbor BRAF and NRAS mutations and copy number changes similar to cutaneous and mucosal melanomas. Clinical cancer research : an official journal of the American Association for Cancer Research. 2013; 19(12):3143-3152. doi: 10.1158/1078-0432.CCR-13-0163. [PubMed: 23633454] 
9. Curtin JA, Busam K, Pinkel D, Bastian BC. Somatic activation of KIT in distinct subtypes of melanoma. Journal of clinical oncology : official journal of the American Society of Clinical Oncology. 2006; 24(26):4340-4346. doi:10.1200/JCO.2006.06.2984. [PubMed: 16908931]

10. Van Raamsdonk CD, Griewank KG, Crosby MB, Garrido MC, Vemula S, Wiesner T, Obenauf AC, Wackernagel W, Green G, Bouvier N, Sozen MM, Baimukanova G, Roy R, Heguy A, Dolgalev I, Khanin R, Busam K, Speicher MR, O'Brien J, Bastian BC. Mutations in GNA11 in uveal melanoma. The New England journal of medicine. 2010; 363(23):2191-2199. doi:10.1056/ NEJMoa1000584. [PubMed: 21083380]

11. Chapman PB, Hauschild A, Robert C, Haanen JB, Ascierto P, Larkin J, Dummer R, Garbe C, Testori A, Maio M, Hogg D, Lorigan P, Lebbe C, Jouary T, Schadendorf D, Ribas A, O'Day SJ, Sosman JA, Kirkwood JM, Eggermont AM, Dreno B, Nolop K, Li J, Nelson B, Hou J, Lee RJ, Flaherty KT, McArthur GA. Improved survival with vemurafenib in melanoma with BRAF V600E mutation. The New England journal of medicine. 2011; 364(26):2507-2516. doi:10.1056/ NEJMoa1103782. [PubMed: 21639808]

12. Hauschild A, Grob JJ, Demidov LV, Jouary T, Gutzmer R, Millward M, Rutkowski P, Blank CU, Miller WH Jr. Kaempgen E, Martin-Algarra S, Karaszewska B, Mauch C, Chiarion-Sileni V, Martin AM, Swann S, Haney P, Mirakhur B, Guckert ME, Goodman V, Chapman PB. Dabrafenib in BRAF-mutated metastatic melanoma: a multicentre, open-label, phase 3 randomised controlled trial. Lancet. 2012; 380(9839):358-365. doi:10.1016/S0140-6736(12)60868-X. [PubMed: 22735384]

13. Rochet NM, Kottschade LA, Markovic SN. Vemurafenib for melanoma metastases to the brain. The New England journal of medicine. 2011; 365(25):2439-2441. doi:10.1056/NEJMc1111672. [PubMed: 22188003]

14. Long GV, Trefzer U, Davies MA, Kefford RF, Ascierto PA, Chapman PB, Puzanov I, Hauschild A, Robert C, Algazi A, Mortier L, Tawbi H, Wilhelm T, Zimmer L, Switzky J, Swann S, Martin AM, Guckert M, Goodman V, Streit M, Kirkwood JM, Schadendorf D. Dabrafenib in patients with Val600Glu or Val600Lys BRAF-mutant melanoma metastatic to the brain (BREAK-MB): a multicentre, open-label, phase 2 trial. The Lancet Oncology. 2012; 13(11):1087-1095. doi: 10.1016/S1470-2045(12)70431-X. [PubMed: 23051966]

15. Flaherty KT, Robert C, Hersey P, Nathan P, Garbe C, Milhem M, Demidov LV, Hassel JC, Rutkowski P, Mohr P, Dummer R, Trefzer U, Larkin JM, Utikal J, Dreno B, Nyakas M, Middleton MR, Becker JC, Casey M, Sherman LJ, Wu FS, Ouellet D, Martin AM, Patel K, Schadendorf D, Group MS. Improved survival with MEK inhibition in BRAF-mutated melanoma. The New England journal of medicine. 2012; 367(2):107-114. doi:10.1056/NEJMoa1203421. [PubMed: 22663011]

16. Flaherty KT, Infante JR, Daud A, Gonzalez R, Kefford RF, Sosman J, Hamid O, Schuchter L, Cebon J, Ibrahim N, Kudchadkar R, Burris HA 3rd, Falchook G, Algazi A, Lewis K, Long GV, Puzanov I, Lebowitz P, Singh A, Little S, Sun P, Allred A, Ouellet D, Kim KB, Patel K, Weber J. Combined BRAF and MEK inhibition in melanoma with BRAF V600 mutations. The New England journal of medicine. 2012; 367(18):1694-1703. doi:10.1056/NEJMoa1210093. [PubMed: 23020132]

17. Robert C, Dummer R, Gutzmer R, Lorigan P, Kim KB, Nyakas M, Arance A, Liszkay G, Schadendorf D, Cantarini M, Spencer S, Middleton MR. Selumetinib plus dacarbazine versus placebo plus dacarbazine as first-line treatment for BRAF-mutant metastatic melanoma: a phase 2 double-blind randomised study. The Lancet Oncology. 2013; 14(8):733-740. doi:10.1016/ S1470-2045(13)70237-7. [PubMed: 23735514]

18. Brugger W, Triller N, Blasinska-Morawiec M, Curescu S, Sakalauskas R, Manikhas GM, Mazieres J, Whittom R, Ward C, Mayne K, Trunzer K, Cappuzzo F. Prospective molecular marker analyses of EGFR and KRAS from a randomized, placebo-controlled study of erlotinib maintenance therapy in advanced non-small-cell lung cancer. Journal of clinical oncology : official journal of the American Society of Clinical Oncology. 2011; 29(31):4113-4120. doi:10.1200/JCO. 2010.31.8162. [PubMed: 21969500]

19. Janne PA, Shaw AT, Pereira JR, Jeannin G, Vansteenkiste J, Barrios C, Franke FA, Grinsted L, Zazulina V, Smith P, Smith I, Crino L. Selumetinib plus docetaxel for KRAS-mutant advanced non-small-cell lung cancer: a randomised, multicentre, placebo-controlled, phase 2 study. The Lancet Oncology. 2013; 14(1):38-47. doi:10.1016/S1470-2045(12)70489-8. [PubMed: 23200175] 
20. Blumenschein G Jr. Smit EF, Planchard D, Kim DW, Cadranel J, De Pas T, Dunphy F, Udud K, Ahn MJ, Hanna NH, Kim JH, Mazieres J, Kim SW, Baas P, Rappold E, Redhu S, Puski A, Wu FS, Janne PA. A randomized phase 2 study of the MEK1/MEK2 inhibitor trametinib (GSK1120212) compared with docetaxel in KRAS-mutant advanced non-small cell lung cancer (NSCLC). Ann Oncol. 2015 doi:10.1093/annonc/mdv072.

21. Cantley LC. The phosphoinositide 3-kinase pathway. Science. 2002; 296(5573):1655-1657. doi: 10.1126/science.296.5573.1655. [PubMed: 12040186]

22. Zhao L, Vogt PK. Helical domain and kinase domain mutations in p110alpha of phosphatidylinositol 3-kinase induce gain of function by different mechanisms. Proceedings of the National Academy of Sciences of the United States of America. 2008; 105(7):2652-2657. doi: 0712169105 [pii] 10.1073/pnas.0712169105. [PubMed: 18268322]

23. Stephens L, Anderson K, Stokoe D, Erdjument-Bromage H, Painter GF, Holmes AB, Gaffney PR, Reese CB, McCormick F, Tempst P, Coadwell J, Hawkins PT. Protein kinase B kinases that mediate phosphatidylinositol 3,4,5-trisphosphate-dependent activation of protein kinase B. Science. 1998; 279(5351):710-714. [PubMed: 9445477]

24. Kim JS, Yun HS, Um HD, Park JK, Lee KH, Kang CM, Lee SJ, Hwang SG. Identification of inositol polyphosphate 4-phosphatase type II as a novel tumor resistance biomarker in human laryngeal cancer HEp-2 cells. Cancer biology \& therapy. 2012; 13(13):1307-1318. doi:10.4161/ cbt.21788. [PubMed: 22895072]

25. Hara K, Maruki Y, Long X, Yoshino K, Oshiro N, Hidayat S, Tokunaga C, Avruch J, Yonezawa K. Raptor, a binding partner of target of rapamycin (TOR), mediates TOR action. Cell. 2002; 110(2): 177-189. [PubMed: 12150926]

26. Hanahan D, Weinberg RA. The hallmarks of cancer. Cell. 2000; 100(1):57-70. [PubMed: 10647931]

27. Baselga J, Campone M, Piccart M, Burris HA 3rd, Rugo HS, Sahmoud T, Noguchi S, Gnant M, Pritchard KI, Lebrun F, Beck JT, Ito Y, Yardley D, Deleu I, Perez A, Bachelot T, Vittori L, Xu Z, Mukhopadhyay P, Lebwohl D, Hortobagyi GN. Everolimus in postmenopausal hormone-receptorpositive advanced breast cancer. The New England journal of medicine. 2012; 366(6):520-529. doi:10.1056/NEJMoa1 109653. [PubMed: 22149876]

28. Wagner, AJVHDH.; Lorusso, PM.; Tibes, R.; Mazina, KE.; Ware, JA., et al. A first-in-human phase I study to evaluate the pan-PI3K inhibitor GDC-0941 administered QD or BID in patients with advanced solid tumors.. ASCO Annual Meeting Proceedings. 2009. .10.1200/JCO. 2008.18.5918

29. Moreno Garcia VBRD, Shah KJ, Basu B, Tunariu N, Blanco M, et al. A phase I study evaluating GDC-0941, an oral phosphoinositide-3 kinase (PI3K) inhibitor, in patients with advanced solid tumors or multiple myeloma. J. Clin. Oncol. 2011; 29:3021. [ASCO Annual Meeting Proceedings].

30. Von Hoff DDLP, Demetri GD, Weiss GJ, Shapiro G, Ramanathan RK, et al. A phase I doseescalation study to evaluate GDC-0941, a pan-PI3K inhibitor, administered QD or BID in patients with advanced or metastatic solid tumors. J. Clin. Oncol. 2011; 29:3052. [ASCO Annual Meeting Proceedings].10.1200/JCO.2011.36.5742.

31. Bendell JC, Rodon J, Burris HA, de Jonge M, Verweij J, Birle D, Demanse D, De Buck SS, Ru QC, Peters M, Goldbrunner M, Baselga J. Phase I, dose-escalation study of BKM120, an oral panClass I PI3K inhibitor, in patients with advanced solid tumors. Journal of clinical oncology : official journal of the American Society of Clinical Oncology. 2012; 30(3):282-290. doi:10.1200/ JCO.2011.36.1360. [PubMed: 22162589]

32. Arkenau H-TJSF, Kurkjian C, Infante JR, Pant S, Burris HA, et al. The PI3K/mTOR inhibitor BEZ235 given twice daily for the treatment of patients (pts) with advanced solid tumors. J. Clin. Oncol. 2012; 30 abstr. 3097. [ASCO Annual Meeting Proceedings].

33. Krop IESC, Ahnert JR, Becerra C, Britten CD, Isakoff SJ, et al. A phase I/IB dose-escalation study of BEZ235 in combination with trastuzumab in patients with PI3-kinase or PTEN altered HER2+ metastatic breast cancer. J. Clin. Oncol. 2012; 30 abstr. 508. [ASCO Annual Meeting Proceedings].10.1200/JCO.2011.40.5902.

34. Carver BS, Chapinski C, Wongvipat J, Hieronymus H, Chen Y, Chandarlapaty S, Arora VK, Le C, Koutcher J, Scher H, Scardino PT, Rosen N, Sawyers CL. Reciprocal feedback regulation of PI3K 
and androgen receptor signaling in PTEN-deficient prostate cancer. Cancer cell. 2011; 19(5):575586. doi:10.1016/j.ccr.2011.04.008. [PubMed: 21575859]

35. Reid AH, Attard G, Ambroisine L, Fisher G, Kovacs G, Brewer D, Clark J, Flohr P, Edwards S, Berney DM, Foster CS, Fletcher A, Gerald WL, Moller H, Reuter VE, Scardino PT, Cuzick J, de Bono JS, Cooper CS, Transatlantic Prostate G. Molecular characterisation of ERG, ETV1 and PTEN gene loci identifies patients at low and high risk of death from prostate cancer. Br J Cancer. 2010; 102(4):678-684. doi:10.1038/sj.bjc.6605554. [PubMed: 20104229]

36. Fritsch C, Huang A, Chatenay-Rivauday C, Schnell C, Reddy A, Liu M, Kauffmann A, Guthy D, Erdmann D, De Pover A, Furet P, Gao H, Ferretti S, Wang Y, Trappe J, Brachmann SM, Maira SM, Wilson C, Boehm M, Garcia-Echeverria C, Chene P, Wiesmann M, Cozens R, Lehar J, Schlegel R, Caravatti G, Hofmann F, Sellers WR. Characterization of the novel and specific PI3Kalpha inhibitor NVP-BYL719 and development of the patient stratification strategy for clinical trials. Molecular cancer therapeutics. 2014; 13(5):1117-1129. doi: 10.1158/1535-7163.MCT-13-0865. [PubMed: 24608574]

37. Juric AAG, Burris HA, et al. Juric D. Phase I study of BYL719, an alpa-specific PI3K inhibitor, in patients with PIK3CA mutant advanced solid tumors: preliminary efficacy and safety in patients with PIK3CA mutant ER-positive (ER+) metastatic breast cancer (MBC). Cancer Res. 2012; 72(24 supplement):P6-10-07. e.a.

38. Hoeflich KP, Merchant M, Orr C, Chan J, Den Otter D, Berry L, Kasman I, Koeppen H, Rice K, Yang NY, Engst S, Johnston S, Friedman LS, Belvin M. Intermittent administration of MEK inhibitor GDC-0973 plus PI3K inhibitor GDC-0941 triggers robust apoptosis and tumor growth inhibition. Cancer research. 2012; 72(1):210-219. doi:10.1158/0008-5472.CAN-11-1515. [PubMed: 22084396]

39. Bedard PL, Tabernero J, Janku F, Wainberg ZA, Paz-Ares L, Vansteenkiste J, Van Cutsem E, Perez-Garcia J, Stathis A, Britten CD, Le N, Carter K, Demanse D, Csonka D, Peters M, Zubel A, Nauwelaerts H, Sessa C. A phase Ib dose-escalation study of the oral pan-PI3K inhibitor buparlisib (BKM120) in combination with the oral MEK1/2 inhibitor trametinib (GSK1120212) in patients with selected advanced solid tumors. Clinical cancer research : an official journal of the American Association for Cancer Research. 2015; 21(4):730-738. doi: 10.1158/1078-0432.CCR-14-1814. [PubMed: 25500057]

40. Ciardiello F, Tortora G. EGFR antagonists in cancer treatment. The New England journal of medicine. 2008; 358(11):1160-1174. doi:358/11/1160 [pii] 10.1056/NEJMra0707704. [PubMed: 18337605]

41. Thatcher N, Chang A, Parikh P, Rodrigues Pereira J, Ciuleanu T, von Pawel J, Thongprasert S, Tan EH, Pemberton K, Archer V, Carroll K. Gefitinib plus best supportive care in previously treated patients with refractory advanced non-small-cell lung cancer: results from a randomised, placebocontrolled, multicentre study (Iressa Survival Evaluation in Lung Cancer). Lancet. 2005; 366(9496):1527-1537. doi:10.1016/S0140-6736(05)67625-8. [PubMed: 16257339]

42. Shepherd FA, Rodrigues Pereira J, Ciuleanu T, Tan EH, Hirsh V, Thongprasert S, Campos D, Maoleekoonpiroj S, Smylie M, Martins R, van Kooten M, Dediu M, Findlay B, Tu D, Johnston D, Bezjak A, Clark G, Santabarbara P, Seymour L, National Cancer Institute of Canada Clinical Trials G. Erlotinib in previously treated non-small-cell lung cancer. The New England journal of medicine. 2005; 353(2):123-132. doi:10.1056/NEJMoa050753. [PubMed: 16014882]

43. Lynch TJ, Bell DW, Sordella R, Gurubhagavatula S, Okimoto RA, Brannigan BW, Harris PL, Haserlat SM, Supko JG, Haluska FG, Louis DN, Christiani DC, Settleman J, Haber DA. Activating mutations in the epidermal growth factor receptor underlying responsiveness of nonsmall-cell lung cancer to gefitinib. The New England journal of medicine. 2004; 350(21):21292139. doi:10.1056/NEJMoa040938 NEJMoa040938 [pii]. [PubMed: 15118073]

44. Paez JG, Janne PA, Lee JC, Tracy S, Greulich H, Gabriel S, Herman P, Kaye FJ, Lindeman N, Boggon TJ, Naoki K, Sasaki H, Fujii Y, Eck MJ, Sellers WR, Johnson BE, Meyerson M. EGFR mutations in lung cancer: correlation with clinical response to gefitinib therapy. Science. 2004; 304(5676):1497-1500. doi:10.1126/science.1099314. [PubMed: 15118125]

45. Sequist LV, Martins RG, Spigel D, Grunberg SM, Spira A, Janne PA, Joshi VA, McCollum D, Evans TL, Muzikansky A, Kuhlmann GL, Han M, Goldberg JS, Settleman J, Iafrate AJ, Engelman JA, Haber DA, Johnson BE, Lynch TJ. First-line gefitinib in patients with advanced non-small-cell 
lung cancer harboring somatic EGFR mutations. Journal of clinical oncology : official journal of the American Society of Clinical Oncology. 2008; 26(15):2442-2449. doi:10.1200/JCO. 2007.14.8494. [PubMed: 18458038]

46. Cappuzzo F, Ligorio C, Janne PA, Toschi L, Rossi E, Trisolini R, Paioli D, Holmes AJ, Magrini E, Finocchiaro G, Bartolini S, Cancellieri A, Ciardiello F, Patelli M, Crino L, Varella-Garcia M. Prospective study of gefitinib in epidermal growth factor receptor fluorescence in situ hybridization-positive/phospho-Akt-positive or never smoker patients with advanced non-smallcell lung cancer: the ONCOBELL trial. Journal of clinical oncology : official journal of the American Society of Clinical Oncology. 2007; 25(16):2248-2255. doi:10.1200/JCO.2006.09.4300. [PubMed: 17538169]

47. Mok TS, Wu YL, Thongprasert S, Yang CH, Chu DT, Saijo N, Sunpaweravong P, Han B, Margono B, Ichinose Y, Nishiwaki Y, Ohe Y, Yang JJ, Chewaskulyong B, Jiang H, Duffield EL, Watkins CL, Armour AA, Fukuoka M. Gefitinib or carboplatin-paclitaxel in pulmonary adenocarcinoma. The New England journal of medicine. 2009; 361(10):947-957. doi:10.1056/NEJMoa0810699. [PubMed: 19692680]

48. Mitsudomi T, Morita S, Yatabe Y, Negoro S, Okamoto I, Tsurutani J, Seto T, Satouchi M, Tada H, Hirashima T, Asami K, Katakami N, Takada M, Yoshioka H, Shibata K, Kudoh S, Shimizu E, Saito H, Toyooka S, Nakagawa K, Fukuoka M, West Japan Oncology G. Gefitinib versus cisplatin plus docetaxel in patients with non-small-cell lung cancer harbouring mutations of the epidermal growth factor receptor (WJTOG3405): an open label, randomised phase 3 trial. The Lancet Oncology. 2010; 11(2):121-128. doi:10.1016/S1470-2045(09)70364-X. [PubMed: 20022809]

49. Maemondo M, Inoue A, Kobayashi K, Sugawara S, Oizumi S, Isobe H, Gemma A, Harada M, Yoshizawa H, Kinoshita I, Fujita Y, Okinaga S, Hirano H, Yoshimori K, Harada T, Ogura T, Ando M, Miyazawa H, Tanaka T, Saijo Y, Hagiwara K, Morita S, Nukiwa T, North-East Japan Study G. Gefitinib or chemotherapy for non-small-cell lung cancer with mutated EGFR. The New England journal of medicine. 2010; 362(25):2380-2388. doi:10.1056/NEJMoa0909530. [PubMed: 20573926]

50. Zhou C, Wu YL, Chen G, Feng J, Liu XQ, Wang C, Zhang S, Wang J, Zhou S, Ren S, Lu S, Zhang L, Hu C, Hu C, Luo Y, Chen L, Ye M, Huang J, Zhi X, Zhang Y, Xiu Q, Ma J, Zhang L, You C. Erlotinib versus chemotherapy as first-line treatment for patients with advanced EGFR mutationpositive non-small-cell lung cancer (OPTIMAL, CTONG-0802): a multicentre, open-label, randomised, phase 3 study. The Lancet Oncology. 2011; 12(8):735-742. doi:10.1016/ S1470-2045(11)70184-X. [PubMed: 21783417]

51. Rosell R, Carcereny E, Gervais R, Vergnenegre A, Massuti B, Felip E, Palmero R, Garcia-Gomez R, Pallares C, Sanchez JM, Porta R, Cobo M, Garrido P, Longo F, Moran T, Insa A, De Marinis F, Corre R, Bover I, Illiano A, Dansin E, de Castro J, Milella M, Reguart N, Altavilla G, Jimenez U, Provencio M, Moreno MA, Terrasa J, Munoz-Langa J, Valdivia J, Isla D, Domine M, Molinier O, Mazieres J, Baize N, Garcia-Campelo R, Robinet G, Rodriguez-Abreu D, Lopez-Vivanco G, Gebbia V, Ferrera-Delgado L, Bombaron P, Bernabe R, Bearz A, Artal A, Cortesi E, Rolfo C, Sanchez-Ronco M, Drozdowskyj A, Queralt C, de Aguirre I, Ramirez JL, Sanchez JJ, Molina MA, Taron M, Paz-Ares L, Spanish Lung Cancer Group in collaboration with Groupe Francais de P-C, Associazione Italiana Oncologia T. Erlotinib versus standard chemotherapy as first-line treatment for European patients with advanced EGFR mutation-positive non-small-cell lung cancer (EURTAC): a multicentre, open-label, randomised phase 3 trial. The Lancet Oncology. 2012; 13(3):239-246. doi:10.1016/S1470-2045(11)70393-X. [PubMed: 22285168]

52. Cappuzzo F, Ciuleanu T, Stelmakh L, Cicenas S, Szczesna A, Juhasz E, Esteban E, Molinier O, Brugger W, Melezinek I, Klingelschmitt G, Klughammer B, Giaccone G, investigators S. Erlotinib as maintenance treatment in advanced non-small-cell lung cancer: a multicentre, randomised, placebo-controlled phase 3 study. The Lancet Oncology. 2010; 11(6):521-529. doi:10.1016/ S1470-2045(10)70112-1. [PubMed: 20493771]

53. Garassino MC, Martelli O, Broggini M, Farina G, Veronese S, Rulli E, Bianchi F, Bettini A, Longo F, Moscetti L, Tomirotti M, Marabese M, Ganzinelli M, Lauricella C, Labianca R, Floriani I, Giaccone G, Torri V, Scanni A, Marsoni S, trialists T. Erlotinib versus docetaxel as second-line treatment of patients with advanced non-small-cell lung cancer and wild-type EGFR tumours (TAILOR): a randomised controlled trial. The Lancet Oncology. 2013; 14(10):981-988. doi: 10.1016/S1470-2045(13)70310-3. [PubMed: 23883922] 
54. Altorki NK, O'brien MER, Eberhardt WEE, Richardson FC, Wang J, Foley MA, Horan JD, Shepherd FA, Kelly K. Adjuvant Erlotinib (E) Versus Placebo (P) for Completely Resected Stage IB-IIIA EGFR-Positive (IHC/FISH) Non-Small Cell Lung Cancer (NSCLC): RADIANT Results. Int J Radiat Oncol. 2014; 90:S2-S3.

55. Richardson F, Richardson K, Sennello G, Young D, Orlov S, Papai-Szekely Z, Keshavjee S, Kim J, Cerfolio R, Shepherd FA. Biomarker analysis from completely resected NSCLC patients enrolled in an adjuvant erlotinib clinical trial (RADIANT). ASCO Meeting Abstracts. 2009; 27(15S):7520.

56. Neal JW, Pennell NA, Govindan R, Lanuti M, Rosovsky RPG, Heist RS, Shaw AT, Temel JS, Muzikansky A, Janne PA, Lynch TJ, Azzoli CG, Sequist LV. The SELECT study: A multicenter phase II trial of adjuvant erlotinib in resected epidermal growth factor receptor (EGFR) mutationpositive non-small cell lung cancer (NSCLC). ASCO Meeting Abstracts. 2012; 30(15_suppl): 7010.

57. Sequist LV, Yang JC, Yamamoto N, O'Byrne K, Hirsh V, Mok T, Geater SL, Orlov S, Tsai CM, Boyer M, Su WC, Bennouna J, Kato T, Gorbunova V, Lee KH, Shah R, Massey D, Zazulina V, Shahidi M, Schuler M. Phase III study of afatinib or cisplatin plus pemetrexed in patients with metastatic lung adenocarcinoma with EGFR mutations. Journal of clinical oncology : official journal of the American Society of Clinical Oncology. 2013; 31(27):3327-3334. doi:10.1200/JCO. 2012.44.2806. [PubMed: 23816960]

58. Sequist LV, Waltman BA, Dias-Santagata D, Digumarthy S, Turke AB, Fidias P, Bergethon K, Shaw AT, Gettinger S, Cosper AK, Akhavanfard S, Heist RS, Temel J, Christensen JG, Wain JC, Lynch TJ, Vernovsky K, Mark EJ, Lanuti M, Iafrate AJ, Mino-Kenudson M, Engelman JA. Genotypic and histological evolution of lung cancers acquiring resistance to EGFR inhibitors. Science translational medicine. 2011; 3(75):75ra26. doi:10.1126/scitranslmed.3002003.

59. Lynch TJ, Patel T, Dreisbach L, McCleod M, Heim WJ, Hermann RC, Paschold E, Iannotti NO, Dakhil S, Gorton S, Pautret V, Weber MR, Woytowitz D. Cetuximab and first-line taxane/ carboplatin chemotherapy in advanced non-small-cell lung cancer: results of the randomized multicenter phase III trial BMS099. Journal of clinical oncology : official journal of the American Society of Clinical Oncology. 2010; 28(6):911-917. doi:10.1200/JCO.2009.21.9618. [PubMed: 20100966]

60. Pirker R, Pereira JR, Szczesna A, von Pawel J, Krzakowski M, Ramlau R, Vynnychenko I, Park K, Yu CT, Ganul V, Roh JK, Bajetta E, O'Byrne K, de Marinis F, Eberhardt W, Goddemeier T, Emig M, Gatzemeier U, Team FS. Cetuximab plus chemotherapy in patients with advanced non-smallcell lung cancer (FLEX): an open-label randomised phase III trial. Lancet. 2009; 373(9674):15251531. doi:10.1016/S0140-6736(09)60569-9. [PubMed: 19410716]

61. Cunningham D, Humblet Y, Siena S, Khayat D, Bleiberg H, Santoro A, Bets D, Mueser M, Harstrick A, Verslype C, Chau I, Van Cutsem E. Cetuximab monotherapy and cetuximab plus irinotecan in irinotecan-refractory metastatic colorectal cancer. The New England journal of medicine. 2004; 351(4):337-345. doi:10.1056/NEJMoa033025. [PubMed: 15269313]

62. Jonker DJ, O'Callaghan CJ, Karapetis CS, Zalcberg JR, Tu D, Au HJ, Berry SR, Krahn M, Price T, Simes RJ, Tebbutt NC, van Hazel G, Wierzbicki R, Langer C, Moore MJ. Cetuximab for the treatment of colorectal cancer. The New England journal of medicine. 2007; 357(20):2040-2048. doi:10.1056/NEJMoa071834. [PubMed: 18003960]

63. Licitra L, Storkel S, Kerr KM, Van Cutsem E, Pirker R, Hirsch FR, Vermorken JB, von Heydebreck A, Esser R, Celik I, Ciardiello F. Predictive value of epidermal growth factor receptor expression for first-line chemotherapy plus cetuximab in patients with head and neck and colorectal cancer: analysis of data from the EXTREME and CRYSTAL studies. European journal of cancer. 2013; 49(6):1161-1168. doi:10.1016/j.ejca.2012.11.018. [PubMed: 23265711]

64. Bokemeyer C, Bondarenko I, Makhson A, Hartmann JT, Aparicio J, de Braud F, Donea S, Ludwig H, Schuch G, Stroh C, Loos AH, Zubel A, Koralewski P. Fluorouracil, leucovorin, and oxaliplatin with and without cetuximab in the first-line treatment of metastatic colorectal cancer. Journal of clinical oncology : official journal of the American Society of Clinical Oncology. 2009; 27(5): 663-671. doi:10.1200/JCO.2008.20.8397. [PubMed: 19114683]

65. Douillard JY, Siena S, Cassidy J, Tabernero J, Burkes R, Barugel M, Humblet Y, Bodoky G, Cunningham D, Jassem J, Rivera F, Kocakova I, Ruff P, Blasinska-Morawiec M, Smakal M, Canon JL, Rother M, Oliner KS, Tian Y, Xu F, Sidhu R. Final results from PRIME: randomized 
phase III study of panitumumab with FOLFOX4 for first-line treatment of metastatic colorectal cancer. Ann Oncol. 2014; 25(7):1346-1355. doi:10.1093/annonc/mdu141. [PubMed: 24718886]

66. Price TJ, Peeters M, Kim TW, Li J, Cascinu S, Ruff P, Suresh AS, Thomas A, Tjulandin S, Zhang K, Murugappan S, Sidhu R. Panitumumab versus cetuximab in patients with chemotherapyrefractory wild-type KRAS exon 2 metastatic colorectal cancer (ASPECCT): a randomised, multicentre, open-label, non-inferiority phase 3 study. The Lancet Oncology. 2014; 15(6):569579. doi:10.1016/S1470-2045(14)70118-4. [PubMed: 24739896]

67. Andersson J, Bumming P, Meis-Kindblom JM, Sihto H, Nupponen N, Joensuu H, Oden A, Gustavsson B, Kindblom LG, Nilsson B. Gastrointestinal stromal tumors with KIT exon 11 deletions are associated with poor prognosis. Gastroenterology. 2006; 130(6):1573-1581. doi: 10.1053/j.gastro.2006.01.043. [PubMed: 16697720]

68. Corless CL, Heinrich MC. Molecular pathobiology of gastrointestinal stromal sarcomas. Annual review of pathology. 2008; 3:557-586. doi:10.1146/annurev.pathmechdis.3.121806.151538.

69. Patel S. Long-term efficacy of imatinib for treatment of metastatic GIST. Cancer chemotherapy and pharmacology. 2013; 72(2):277-286. doi:10.1007/s00280-013-2135-8. [PubMed: 23503753]

70. Heinrich MC, Corless CL, Demetri GD, Blanke CD, von Mehren M, Joensuu H, McGreevey LS, Chen CJ, Van den Abbeele AD, Druker BJ, Kiese B, Eisenberg B, Roberts PJ, Singer S, Fletcher CD, Silberman S, Dimitrijevic S, Fletcher JA. Kinase mutations and imatinib response in patients with metastatic gastrointestinal stromal tumor. Journal of clinical oncology : official journal of the American Society of Clinical Oncology. 2003; 21(23):4342-4349. doi:10.1200/JCO.2003.04.190. [PubMed: 14645423]

71. Corless CL, Barnett CM, Heinrich MC. Gastrointestinal stromal tumours: origin and molecular oncology. Nature reviews Cancer. 2011; 11(12):865-878. doi:10.1038/nrc3143. [PubMed: 22089421]

72. Demetri GD, van Oosterom AT, Garrett CR, Blackstein ME, Shah MH, Verweij J, McArthur G, Judson IR, Heinrich MC, Morgan JA, Desai J, Fletcher CD, George S, Bello CL, Huang X, Baum CM, Casali PG. Efficacy and safety of sunitinib in patients with advanced gastrointestinal stromal tumour after failure of imatinib: a randomised controlled trial. Lancet. 2006; 368(9544):13291338. doi:10.1016/S0140-6736(06)69446-4. [PubMed: 17046465]

73. Demetri GD, Reichardt P, Kang YK, Blay JY, Rutkowski P, Gelderblom H, Hohenberger P, Leahy M, von Mehren M, Joensuu H, Badalamenti G, Blackstein M, Le Cesne A, Schoffski P, Maki RG, Bauer S, Nguyen BB, Xu J, Nishida T, Chung J, Kappeler C, Kuss I, Laurent D, Casali PG, investigators Gs. Efficacy and safety of regorafenib for advanced gastrointestinal stromal tumours after failure of imatinib and sunitinib (GRID): an international, multicentre, randomised, placebocontrolled, phase 3 trial. Lancet. 2013; 381(9863):295-302. doi:10.1016/S0140-6736 (12)61857-1. [PubMed: 23177515]

74. Reichardt P, Blay JY, Gelderblom H, Schlemmer M, Demetri GD, Bui-Nguyen B, McArthur GA, Yazji S, Hsu Y, Galetic I, Rutkowski P. Phase III study of nilotinib versus best supportive care with or without a TKI in patients with gastrointestinal stromal tumors resistant to or intolerant of imatinib and sunitinib. Ann Oncol. 2012; 23(7):1680-1687. doi:10.1093/annonc/mdr598. [PubMed: 22357255]

75. Guo J, Si L, Kong Y, Flaherty KT, Xu X, Zhu Y, Corless CL, Li L, Li H, Sheng X, Cui C, Chi Z, Li S, Han M, Mao L, Lin X, Du N, Zhang X, Li J, Wang B, Qin S. Phase II, open-label, single-arm trial of imatinib mesylate in patients with metastatic melanoma harboring c-Kit mutation or amplification. Journal of clinical oncology : official journal of the American Society of Clinical Oncology. 2011; 29(21):2904-2909. doi:10.1200/JCO.2010.33.9275. [PubMed: 21690468]

76. Minor DR, Kashani-Sabet M, Garrido M, O'Day SJ, Hamid O, Bastian BC. Sunitinib therapy for melanoma patients with KIT mutations. Clinical cancer research : an official journal of the American Association for Cancer Research. 2012; 18(5):1457-1463. doi:

10.1158/1078-0432.CCR-11-1987. [PubMed: 22261812]

77. Cho JH, Kim KM, Kwon M, Kim JH, Lee J. Nilotinib in patients with metastatic melanoma harboring KIT gene aberration. Invest New Drugs. 2012; 30(5):2008-2014. doi:10.1007/ s10637-011-9763-9. [PubMed: 22068222]

78. Verstovsek S, Tefferi A, Cortes J, O'Brien S, Garcia-Manero G, Pardanani A, Akin C, Faderl S, Manshouri T, Thomas D, Kantarjian H. Phase II study of dasatinib in Philadelphia chromosome- 
negative acute and chronic myeloid diseases, including systemic mastocytosis. Clinical cancer research : an official journal of the American Association for Cancer Research. 2008; 14(12): 3906-3915. doi:10.1158/1078-0432.CCR-08-0366. [PubMed: 18559612]

79. Jeselsohn R, Yelensky R, Buchwalter G, Frampton G, Meric-Bernstam F, Gonzalez-Angulo AM, Ferrer-Lozano J, Perez-Fidalgo JA, Cristofanilli M, Gomez H, Arteaga CL, Giltnane J, Balko JM, Cronin MT, Jarosz M, Sun J, Hawryluk M, Lipson D, Otto G, Ross JS, Dvir A, Soussan-Gutman L, Wolf I, Rubinek T, Gilmore L, Schnitt S, Come SE, Pusztai L, Stephens P, Brown M, Miller VA. Emergence of constitutively active estrogen receptor-alpha mutations in pretreated advanced estrogen receptor-positive breast cancer. Clinical cancer research : an official journal of the American Association for Cancer Research. 2014; 20(7):1757-1767. doi: 10.1158/1078-0432.CCR-13-2332. [PubMed: 24398047]

80. Slamon DJ, Clark GM, Wong SG, Levin WJ, Ullrich A, McGuire WL. Human breast cancer: correlation of relapse and survival with amplification of the HER-2/neu oncogene. Science. 1987; 235(4785):177-182. [PubMed: 3798106]

81. Mustacchi G, Biganzoli L, Pronzato P, Montemurro F, Dambrosio M, Minelli M, Molteni L, Scaltriti L. HER2-positive metastatic breast cancer: A changing scenario. Critical reviews in oncology/hematology. 2015 doi:10.1016/j.critrevonc.2015.02.002.

82. Tutt A, Robson M, Garber JE, Domchek SM, Audeh MW, Weitzel JN, Friedlander M, Arun B, Loman N, Schmutzler RK, Wardley A, Mitchell G, Earl H, Wickens M, Carmichael J. Oral poly(ADP-ribose) polymerase inhibitor olaparib in patients with BRCA1 or BRCA2 mutations and advanced breast cancer: a proof-of-concept trial. Lancet. 2010; 376(9737):235-244. doi:10.1016/ S0140-6736(10)60892-6. [PubMed: 20609467]

83. Di Renzo MF, Olivero M, Giacomini A, Porte H, Chastre E, Mirossay L, Nordlinger B, Bretti S, Bottardi S, Giordano S, et al. Overexpression and amplification of the met/HGF receptor gene during the progression of colorectal cancer. Clinical cancer research : an official journal of the American Association for Cancer Research. 1995; 1(2):147-154. [PubMed: 9815967]

84. Di Renzo MF, Olivero M, Martone T, Maffe A, Maggiora P, Stefani AD, Valente G, Giordano S, Cortesina G, Comoglio PM. Somatic mutations of the MET oncogene are selected during metastatic spread of human HNSC carcinomas. Oncogene. 2000; 19(12):1547-1555. doi:10.1038/ sj.onc.1203455. [PubMed: 10734314]

85. Boon EM, van der Neut R, van de Wetering M, Clevers H, Pals ST. Wnt signaling regulates expression of the receptor tyrosine kinase met in colorectal cancer. Cancer research. 2002; 62(18): 5126-5128. [PubMed: 12234972]

86. Engelman JA, Zejnullahu K, Mitsudomi T, Song Y, Hyland C, Park JO, Lindeman N, Gale CM, Zhao X, Christensen J, Kosaka T, Holmes AJ, Rogers AM, Cappuzzo F, Mok T, Lee C, Johnson BE, Cantley LC, Janne PA. MET amplification leads to gefitinib resistance in lung cancer by activating ERBB3 signaling. Science. 2007; 316(5827):1039-1043. doi:1141478 [pii] 10.1126/ science.1141478. [PubMed: 17463250]

87. Bean J, Brennan C, Shih JY, Riely G, Viale A, Wang L, Chitale D, Motoi N, Szoke J, Broderick S, Balak M, Chang WC, Yu CJ, Gazdar A, Pass H, Rusch V, Gerald W, Huang SF, Yang PC, Miller V, Ladanyi M, Yang CH, Pao W. MET amplification occurs with or without T790M mutations in EGFR mutant lung tumors with acquired resistance to gefitinib or erlotinib. Proceedings of the National Academy of Sciences of the United States of America. 2007; 104(52):20932-20937. doi: 10.1073/pnas.0710370104. [PubMed: 18093943]

88. Shojaei F, Lee JH, Simmons BH, Wong A, Esparza CO, Plumlee PA, Feng J, Stewart AE, HuLowe DD, Christensen JG. HGF/c-Met acts as an alternative angiogenic pathway in sunitinibresistant tumors. Cancer research. 2010; 70(24):10090-10100. doi: 10.1158/0008-5472.CAN-10-0489. [PubMed: 20952508]

89. Shaw AT, Kim DW, Nakagawa K, Seto T, Crino L, Ahn MJ, De Pas T, Besse B, Solomon BJ, Blackhall F, Wu YL, Thomas M, O'Byrne KJ, Moro-Sibilot D, Camidge DR, Mok T, Hirsh V, Riely GJ, Iyer S, Tassell V, Polli A, Wilner KD, Janne PA. Crizotinib versus chemotherapy in advanced ALK-positive lung cancer. The New England journal of medicine. 2013; 368(25):23852394. doi:10.1056/NEJMoa1214886. [PubMed: 23724913]

90. Shaw AT, Yeap BY, Solomon BJ, Riely GJ, Gainor J, Engelman JA, Shapiro GI, Costa DB, Ou SH, Butaney M, Salgia R, Maki RG, Varella-Garcia M, Doebele RC, Bang YJ, Kulig K, Selaru P, Tang 
Y, Wilner KD, Kwak EL, Clark JW, Iafrate AJ, Camidge DR. Effect of crizotinib on overall survival in patients with advanced non-small-cell lung cancer harbouring ALK gene rearrangement: a retrospective analysis. The Lancet Oncology. 2011; 12(11):1004-1012. doi:S1470-2045(11)70232-7 [pii] 10.1016/S1470-2045(11)70232-7. [PubMed: 21933749]

91. Shaw ATMR, Kim D-W, et al. Clinical activity of the ALK inhibitor LDK378 in advanced, ALKpositive NSCLC. ASCO Meeting Abstracts. 2013; 31:8010.

92. Socinski MA, Goldman J, El-Hariry I, Koczywas M, Vukovic V, Horn L, Paschold E, Salgia R, West H, Sequist LV, Bonomi P, Brahmer J, Chen LC, Sandler A, Belani CP, Webb T, Harper H, Huberman M, Ramalingam S, Wong KK, Teofilovici F, Guo W, Shapiro GI. A multicenter phase II study of ganetespib monotherapy in patients with genotypically defined advanced non-small cell lung cancer. Clinical cancer research : an official journal of the American Association for Cancer Research. 2013; 19(11):3068-3077. doi:10.1158/1078-0432.CCR-12-3381. [PubMed: 23553849]

93. Greenwald I. Structure/function studies of lin-12/Notch proteins. Current opinion in genetics \& development. 1994; 4(4):556-562. [PubMed: 7950324]

94. Rugo, HS.; Olopade, O.; DeMichele, A.; van 't Veer, L.; Buxton, MB.; Hylton, N.; Yee, D.; Chien, AJ.; Wallace, A.; PI's I-SS. Lyandres, J.; Davis, S.; Sanil, A.; Berry, D.; Esserman, L. Veliparib/ carboplatin plus standard neoadjuvant therapy for high-risk breast cancer: First efficacy results from the I-SPY 2 TRIAL.. 36th Annual San Antonio Breast Cancer Symposium. 2013. Abstract S5-02

95. Chang J, Liu X, Wang S, Zhang Z, Wu Z, Zhang X, Li J. Prognostic value of FGFR gene amplification in patients with different types of cancer: a systematic review and meta-analysis. PloS one. 2014; 9(8):e105524. doi:10.1371/journal.pone.0105524. [PubMed: 25171497]

96. Powell MA, Sill MW, Goodfellow PJ, Benbrook DM, Lankes HA, Leslie KK, Jeske Y, Mannel RS, Spillman MA, Lee PS, Hoffman JS, McMeekin DS, Pollock PM. A phase II trial of brivanib in recurrent or persistent endometrial cancer: an NRG Oncology/Gynecologic Oncology Group Study. Gynecologic oncology. 2014; 135(1):38-43. doi:10.1016/j.ygyno.2014.07.083. [PubMed: 25019571]

97. Escudier B, Grunwald V, Ravaud A, Ou YC, Castellano D, Lin CC, Gschwend JE, Harzstark A, Beall S, Pirotta N, Squires M, Shi M, Angevin E. Phase II results of Dovitinib (TKI258) in patients with metastatic renal cell cancer. Clinical cancer research : an official journal of the American Association for Cancer Research. 2014; 20(11):3012-3022. doi:

10.1158/1078-0432.CCR-13-3006. [PubMed: 24691021]

98. Yee D. Insulin-like growth factor receptor inhibitors: baby or the bathwater? Journal of the National Cancer Institute. 2012; 104(13):975-981. doi:10.1093/jnci/djs258. [PubMed: 22761272]

99. Tsimberidou AM, Ringborg U, Schilsky RL. Strategies to overcome clinical, regulatory, and financial challenges in the implementation of personalized medicine. Am Soc Clin Oncol Educ Book. 2013:118-125. doi:10.1200/EdBook_AM.2013.33.118. [PubMed: 23714475]

100. Tsimberidou AM, Wen S, Hong DS, Wheler JJ, Falchook GS, Fu S, Piha-Paul S, Naing A, Janku F, Aldape K, Ye Y, Kurzrock R, Berry D. Personalized medicine for patients with advanced cancer in the phase I program at MD Anderson: validation and landmark analyses. Clinical cancer research : an official journal of the American Association for Cancer Research. 2014; 20(18):4827-4836. doi:10.1158/1078-0432.CCR-14-0603. [PubMed: 24987059] 
Table 1

FDA-approved and selected investigational targeted agents by molecular target/pathway

\begin{tabular}{|c|c|c|}
\hline Pathway/Target & FDA-Approved Drugs & Investigational Agents \\
\hline \multicolumn{3}{|c|}{ RAS-RAF-MEK Pathway } \\
\hline \multirow[t]{3}{*}{ BRAF } & Dabrafenib (Tafinlar) & Encorafenib (LGX818) \\
\hline & Vemurafenib (Zelboraf) & GDC-0879 \\
\hline & & PLX-4720 \\
\hline \multirow[t]{2}{*}{ MEK } & Trametinib (Mekinist) & Cobimetinib (GDC-0973) \\
\hline & & Selumetinib (AZD6244) \\
\hline \multirow[t]{2}{*}{ RAS } & & Tipifarnib \\
\hline & & Lonafarnib \\
\hline \multicolumn{3}{|c|}{ PI3K/AKT/mTOR Pathway } \\
\hline \multirow[t]{4}{*}{ mTOR } & Everolimus (Afinitor) & MLN0128 \\
\hline & Temsirolimus (Torisel) & JNK128 \\
\hline & & AZD8055 \\
\hline & & Ridaforolimus \\
\hline \multirow[t]{7}{*}{ PI3K } & & BKM120 \\
\hline & & Copanlisib (BAY 80-6946) \\
\hline & & XL-147 \\
\hline & & GDC-0032 (Taselisib) \\
\hline & & INK1117 \\
\hline & & BYL719 \\
\hline & & GDC-0941 \\
\hline \multirow[t]{5}{*}{$\mathrm{PI} 3 \mathrm{~K}$ and $\mathrm{mTOR}$} & & BEZ235 \\
\hline & & $\mathrm{XL}-765$ \\
\hline & & BGT-226 \\
\hline & & GDC-0980 \\
\hline & & PF4691502 \\
\hline \multirow[t]{4}{*}{ AKT } & & MK2206 \\
\hline & & GSK2141795 \\
\hline & & BAY1125976 \\
\hline & & GDC-0068 \\
\hline $\mathrm{p} 70 \mathrm{~S} 6 \mathrm{~K} / \mathrm{AKT}$ & & MSC2363318A \\
\hline \multicolumn{3}{|l|}{ BRCA } \\
\hline \multirow[t]{3}{*}{ PARP } & Olaparib (Lynparza) & ABT-888 (Veliparib) \\
\hline & & PF-01367338 (Rucaparib) \\
\hline & & BMN 673 (Talazoparib) \\
\hline Target & FDA-Approved Drugs & Investigational Agents \\
\hline \multirow[t]{2}{*}{ EGFR } & Cetuximab (Erbitux) & CO-1686 (rociletinib) \\
\hline & Erlotinib (Tarceva) & \\
\hline
\end{tabular}




\begin{tabular}{|c|c|c|}
\hline Pathway/Target & FDA-Approved Drugs & Investigational Agents \\
\hline & Afatinib (Gilotrif) & \\
\hline & Panitumumab (Vectibix) & \\
\hline EGFR, RET, VEGFR2 & Vandetanib (Caprelsa) & \\
\hline \multirow[t]{2}{*}{ HER2 } & Pertuzumab (Perjeta) & \\
\hline & Trastuzumab (Herceptin) & \\
\hline HER2 \& EGFR & Lapatinib (Tykerb) & \\
\hline \multirow[t]{5}{*}{ ALK } & Ceritinib (Zykadia) & Alectinib \\
\hline & Crizotinib (Xalkori) & AP26113 (Brigatinib) \\
\hline & & ASP3026 \\
\hline & & PF-06463922 \\
\hline & & $\mathrm{X}-396$ \\
\hline \multirow[t]{5}{*}{ NOTCH } & & Tarextumab (OMP-59R5) \\
\hline & & OMP-21M18 (demcizumab) \\
\hline & & MK-0752 \\
\hline & & RO4929097 \\
\hline & & PF-03084014 \\
\hline \multirow[t]{3}{*}{ KIT, PDGFR, ABL } & Imatinib (Gleevec) & Bosutinib (Bosulif) \\
\hline & Dasatinib (Sprycel) & \\
\hline & Ponatinib (Iclusig) & \\
\hline \multirow[t]{2}{*}{ KIT, PDGFR $\beta$, RAF, RET, VEGFR $1 / 2 / 3$} & Regorafenib (Stivarga) & Dovitinib \\
\hline & Sorafenib (Nexavar) & \\
\hline VEGF ligand & Bevacizumab (Avastin) & \\
\hline Receptor tyrosine kinase (RTK) inhibitor & Sunitinib (Sutent) & \\
\hline VEGF & Nintedanib(Ofev) & Brivanib (BMS-540215) \\
\hline Target & FDA-Approved Drugs & Investigational Agents \\
\hline \multirow[t]{14}{*}{ MET } & & AMG102 (Rilotumumab) \\
\hline & & AV-299 (Ficlatuzumab) \\
\hline & & MetMab (Onartuzumab) \\
\hline & & LY-2875358 \\
\hline & & h224G11A \\
\hline & & DN30 \\
\hline & & MGCD-265 \\
\hline & & Tivantinib (ARQ197 \\
\hline & & JNJ-38877605 \\
\hline & & AMG 337 \\
\hline & & AMG 208 \\
\hline & & PF-04217903 \\
\hline & & EMD-1214063 \\
\hline & & LY-2801653 \\
\hline
\end{tabular}




\begin{tabular}{|c|c|c|}
\hline Pathway/Target & FDA-Approved Drugs & Investigational Agents \\
\hline & & INC-280 \\
\hline & & Foretinib (GSK1363089) \\
\hline & & Cabozantinib (Cometriq) \\
\hline \multirow[t]{17}{*}{ FGF } & & Brivanib \\
\hline & & Dovitinib (TKI258) \\
\hline & & AZD4547 \\
\hline & & BAY1187982 \\
\hline & & Lucitanib \\
\hline & & Ponatinib (Iclusig) \\
\hline & & TAS-120 \\
\hline & & Debio 1347 (CH5183284) \\
\hline & & BAY1163877 \\
\hline & & FGF401 \\
\hline & & BGJ398 \\
\hline & & Nintedanib (BIBF1120) \\
\hline & & JNJ-42756493 \\
\hline & & GSK3052230 \\
\hline & & ARQ 087 \\
\hline & & BAY1179470 \\
\hline & & FPA144 \\
\hline \multirow[t]{5}{*}{ P53 MDM2 } & & DS-3032b \\
\hline & & RO6839921 \\
\hline & & RO5045337 \\
\hline & & RO5503781 \\
\hline & & HDM201 \\
\hline
\end{tabular}

